\title{
EXAMINATION OF HORSES AS TO SOUNDNESS AND \\ SELECTION AS TO PURCHASE
}

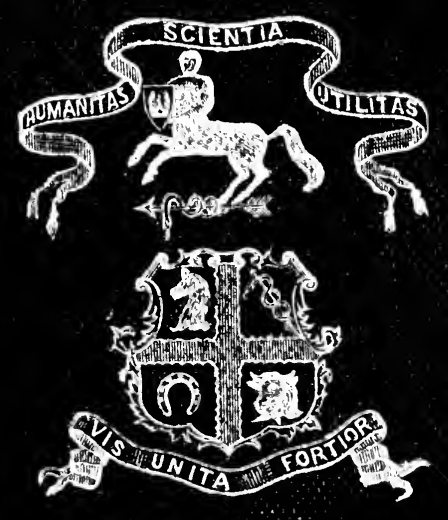

EDWARD SEWELL, M.R.C.V.S.L. 


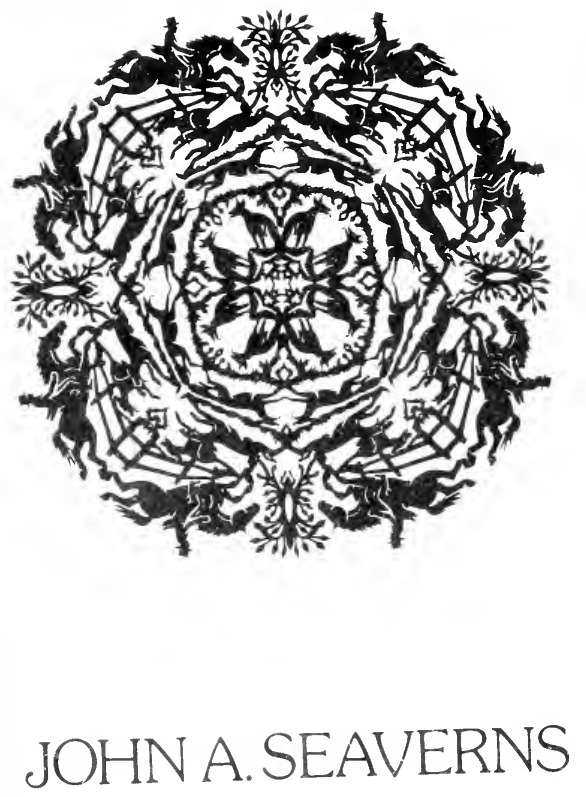


Webrer taitisy vedinine

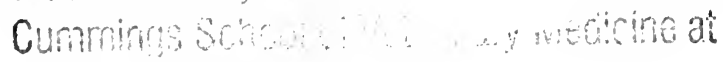

Tuftellater.

2001800

Nort: 


\section{THE EXAMINATION OF HORSES AS TO SOUNDNESS; \\ AND SELECTION AS TO PURCHASE.}




$$
\text { . }
$$




\section{THE EXAIINATION OF HORSES AS TO SOUNDNESS;}

\section{AND SELECTION AS TO PURCHASE.}

BY

EDWARD SEWELL, M.R.C.V.S.L.

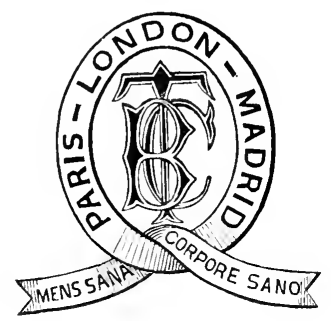

LONDON :

BAILLIÈR, TINDALL AND COX, 20 \& 21, King William Street, Strand.

[PARIS AND MADRID.]

1898.

[All rights reserved.] 



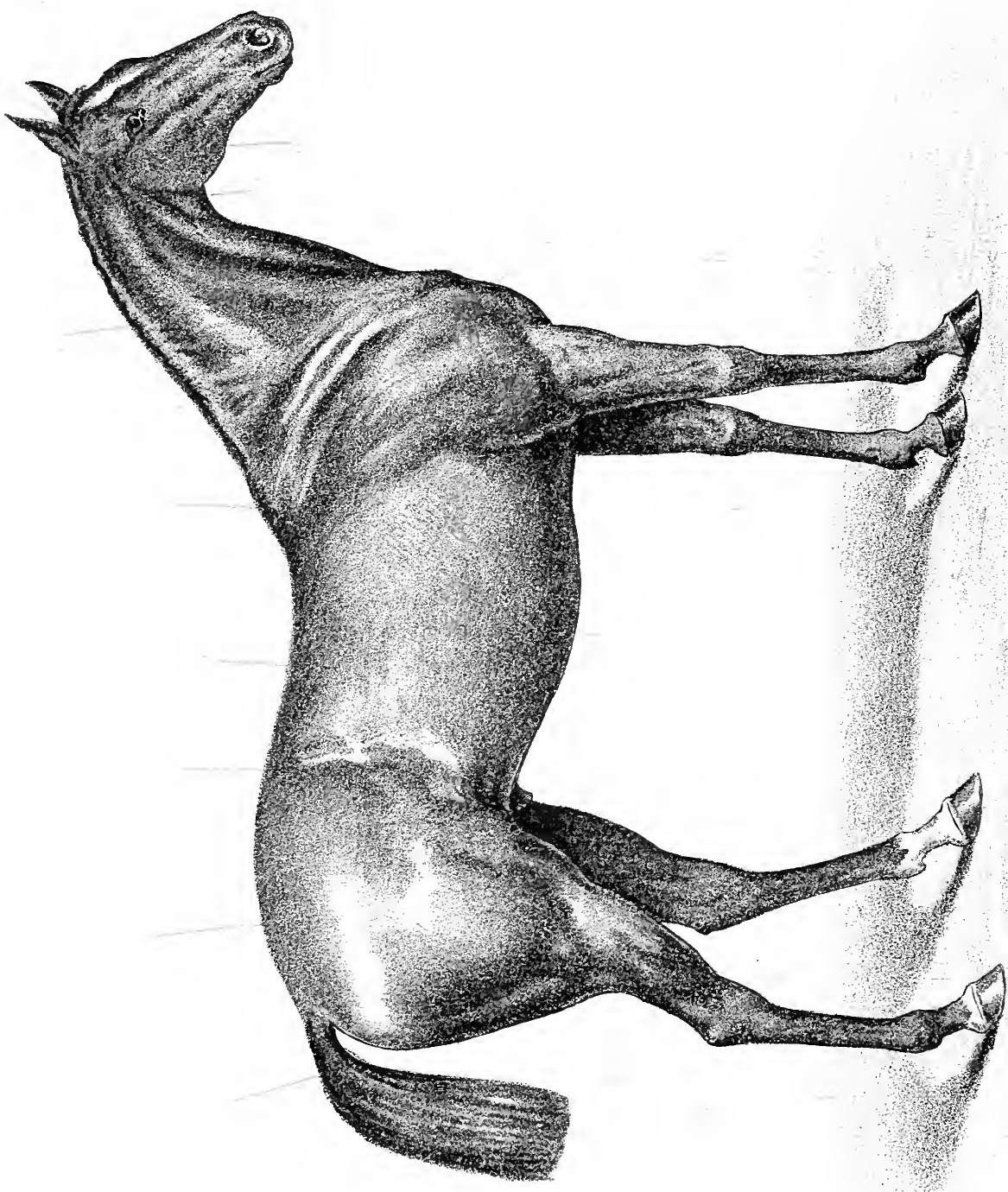



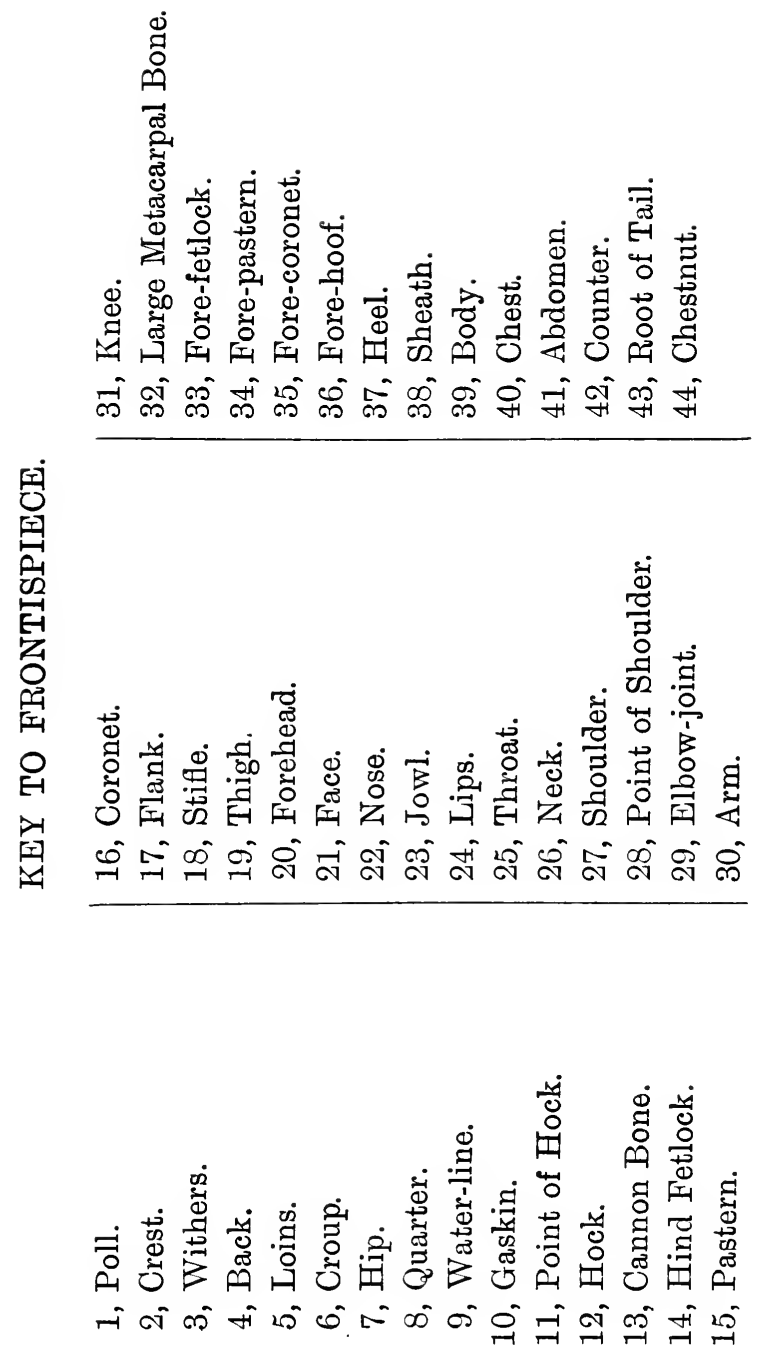



\section{O N T E N TS.}

CHAPTER I.

Mode of examination-Marks of identification-Colour and sex - Eyes - Fore-leg - Knees - SplintsFlexor tendons - Fetlock - joint - Wind-galls Speedy - cut - Ring-bone - Overreach - TreadQuittor-Side-bone-The foot_Laminitis-Seedytoe-False quarter-Sandcrack-Dropped solesCorns-Frog $11-28$

CHAPTER II.

The withers-Back and girth-Warts $29-31$

\section{CHAPTER III.}

The hind-leg - Stifle-joint - Curb - Spavins - Bonespavin-Bog-spavin-Blood-spavin-Capped hock

-Thoroughpin

... $\quad \ldots$

32-38

CHAPTER IV.

Action-Brushing-Cutting and stringhalt-Dishing-

High action

39-44 


\section{CHAPTER V.}

PAGE

Examination of the respiratory apparatus-Manner of testing the wind-Broken wind-Roaring-Whist. ling and grunting-High blowing and chronic $\begin{array}{llllll}\text { cough } & \ldots & \ldots & \ldots & \ldots & 45-50\end{array}$

\section{CHAPTER VI.}

Conformation - The head - Eyes - Ears - NeckWithers-Chest-Shoulders-The arms-Fetlock and pastern - Back - Loins - Ribs-Hips-The hind-quarters-Hock-The body and tail

\section{CHAPTER VII.}

The age of the horse-Component parts of the teethArrangement of the teeth-The temporary or milk teeth-The wolf teeth-The tushes-Arrangement of the teeth at birth-Six weeks-Six monthsNine months-One year-One year and six months -Two years-Three years-Three years offRising four, and four years-Rising five-Five years and five years off-Six years-Six years off —Seven years off_Eight years off $\quad$... $\quad 63-86$ 


\section{PLATES.}

Plate 1. Frontispiece, showing Conformation of the Horse.

„2. Showng Tables of the Teeth at Four Years,

Five Years, and Six Years Old.

"3. One Year Old, Two Years Old.

"4. Three Years Old, Three Years off.

„5. Rising Four Years, and Four Years Old.

„6. Rising Five Years, and Five Years Old.

"7. Five Years off, Six Years off.

„8. Seven Years off, and Eight Years off. 



\section{P R E F A C E.}

In offering this treatise to the public, my idea is to assist the horse-owner, the farmer, and the colonist to judge for himself as to the practical soundness of a horse he may be interested infor it is not always convenient, or even practical, to send for the veterinary surgeon whenever a horse has to be looked over-and I shall endeavour to make myself as clear as possible to this class of my readers, avoiding as far as I can all technicalities with this purpose in view.

I trust this book may be found useful particularly to colonists, for I myself have frequently seen in New Zealand, where I was for some little time, the great difficulty experienced in selecting good sound animals for work and for breeding purposes when purchasing them, owing 
to a want of a little knowledge of the art of examining horses as to soundness on the part of the purchaser, especially amongst the fresh arrivals or new-chums.

38, Thurloe Place, South Kensington,

LoNDon, S.W. 


\section{CHAPTER I.}

\section{EXA M I N A T I O N.}

Is beginning the examination of a horse as to soundness, let the animal be brought out of the stable into the open daylight; and it is always wise to have a memoranda-book and pencil, in order to make notes of what one sees. The groom holding the horse should stand well in front of the animal, so, as you stand a few paces off, you may get a clear and unbroken view of it.

First note the colour; then the sex-horse, mare, or gelding; and also any particular markings upon it (marks of identification) which will enable you to identify the animal, if necessary, at some future time. This is all-important, for if any dispute should arise at some later period as to the identity of this particular animal, all 
doubts can be set at rest by reference to your note-book.

Marks of Identification.-A horse with a white spot upon his forehead is said to have a star. A large white broad line down the face is termed a blaze, whilst a narrow white line is termed a race or raphe. A white patch on the nose or upper lip, often extending to the lower lip, is called a snip. Besides these distinctive marks, note is to be taken whether the horse has white heels or fetlocks, or if any of the feet are white, and also of any other particular marks you may see which would help you to recognise the animal again.

Colour.-In determining the colour of a horse in some cases, to be strictly correct, the colour of the muzzle decides it-for instance, a horse with a black body and brown nose is a brown horse, and a horse with a black muzzle and a brown body is a black horse.

After carefully noting the colour, sex, and marks of identification, the age should be ascertained, and I think the best way I can teach my readers to tell the age of a horse is through the 
medium of some good plates, a number of which, with descriptive notes, will be found at the latter part of the book.

The age satisfactorily ascertained, the next thing to do is to examine the eyes.

Eyes.-In making the examination of the eyes, the horse should, where it is practicable, be stood in some shed or loose-box, with his head just brought to the door, in order that the eyes may be shaded from the full light, which enables one to detect the more readily any defects that may be present. The crown of a silk or black hat makes an excellent screen, held just in front and at the side of the eye for the same purpose.

The anterior part of the eye, or cornea, should be first carefully examined, and blemishes or opacities looked for, for if these are present, and in the direct line of sight, the animal would in all probability be a bad shyer; but should they not be in the line of sight, and are small, they need not be taken too much into account, as for all practical purposes the usefulness of the horse would not be seriously interfered with, although 
a veterinary surgeon would be quite right in rejecting as unsound any horse with an eye so affected; and, indeed, he ought to do so, even if it were only for his own protection. But, as I have already stated, blemishes on the cornea, unless they come in the line of sight, will not practically interfere with the usefulness of the horse.

Having carefully examined the cornea and the eyelids and membranes, search should be made deep into the eye for cataract, a disease of the crystalline lens, whereby the lens becomes opaque or white. Unless the cataract is very small, it may be easily detected by the examiner, if he has good eyesight himself; but in cases where the cataract is so small as not to be readily seen, and if one is suspicious that a cataract is present, a very good plan is to apply the lighted-candle test. In the sound eye three reflections of the flame are distinctly visibletwo erect, and one inverted. The first erect image is caused by a reflection of the flame on the anterior part of the eye or cornea; the second erect image is produced by the reflection 
on the anterior part of the crystalline lens; whilst the third image, which is inverted, is produced by a reflection from the posterior part of the lens.

When the candle is moved, the two erect images move in the same direction as the candle, but the inverted one moves in the opposite direction.

When cataract is present, the inverted image is rendered very indistinct, or is frequently absent altogether, and this applies to the second erect image also. This test is a very sure one, and may be perfectly well relied upon. A horse suffering from cataract should never be purchased if required for fast work, and especially for hunting, inasmuch as defective vision in an animal wanted for these purposes is sure to lead to an accident. But for work on a farm or slow draught work it is immaterial. Cataracts are undoubtedly hereditary, and the presence of one in the eye of a stallion or brood mare renders the animal useless as a sound stockgetter.

Fore-leg.-After making a careful examination 
of the eyes, the limbs are next dealt with, and it must be remembered that defects of the legs may be much more readily detected by careful manipulation than by sheer observation alone. I always make it a practice to commence with the off fore-leg; most people, I believe, begin with the near, but I always start with the off, as I think it more convenient. The hand should first be run over the shoulder, looking for galls thereupon, and from thence down the arm to the knee.

The Knees. - The knees should be very carefully examined for scars, indicating that at some time the horse has fallen down and broken them, for if once a horse has broken his knee, he invariably remains stiff or weak in that particular joint, and stumbles thereby, generally being liable to fall again. This holds good in the great majority of cases, for I have known the parts heal up beautifully, yet the horse always remain a stumbler. Very often hair will be rubbed off the knee by the manner or way the animal has of lying down. Some horses have a habit of scraping the bedding away from under 
them before resting, and these places on the knee are apt to mislead one as to their true character. They are, of course, quite unimportant, but look unsightly, and may readily be distinguished by careful observation from the scars of the broken knee.

Splints.-Passing from the knee, the hand is run down that part of the limb beneath it, firstly in search of a splint, a bony excrescence, and usually found on the inside of the limb. The size and position of a splint have everything to do with the amount of importance that is to be attached to its presence. If the splint is but of small dimensions, and is situated well forward on the bone, and on pressure being applied to it the animal does not flinch, no importance need be attached to it, although in the eye of the law a splint is an unsoundness. If, on the other hand, it is large, and situated towards the back of the bone, so as to be near the tendons, it is a rather serious matter, as it may interfere with the action of the tendons and cause the horse to go lame. A splint that is situated high up and close to the knee is also bad, and an animal 
should be avoided that is so affected, as the bony matter often involves the small bones of the knee, cementing them together and causing lameness which is as a rule incurable; but, as has been already stated, if the splint is not large, and is situated well forward on the bone, and the animal trots soundly, not much importance need be attached to it, especially if the horse is of any age. After satisfying one's self as to the presence of splints, pass the hand carefully down the back or flexor tendons, noting at the same time whether these are enlarged; should they be so, apply pressure, and if this is painful to the horse, have nothing to do with it. Very often, especially in aged animals, the flexors are a little enlarged from the sheath of the tendons becoming somewhat thickened, and if this is only slight, and no pain is evinced on pressure, and the animal trots out soundly, not much importance need be attached to it, as the horse will probably work all right. A veterinary surgeon, of course, would not pass a horse so affected as being sound, but would probably tell the intending purchaser that the animal would work well without being 
troubled. The tendons having been carefully examined, the next thing to look to is the fetlockjoint.

Fetlock-joint.-This should be carefully manipulated, and note taken as to whether it is enlarged from work or other causes. Round, puffy fetlocks are very undesirable, as this condition denotes weakness, and the animal may fall lame from them at any time, and such lameness would give a lot of trouble, invariably requiring blistering, or even firing and blistering, to get the animal sound again in its action, and this means a long time for the horse to remain under treatment.

Wind-galls.--In examining the fetlock, note should be taken of the presence of any windgalls, which are bursal enlargements affecting the joint. They denote, as a rule, that the animal has done a considerable amount of work, and are not usually a cause of lameness, unless very pronounced. If they are large, the horse should be cast as likely to go lame.

Speedy-cut.-When passing the hand down the leg, a careful examination should be made 
for speedy-cut, which is usually caused by the shoe of the opposite foot coming in contact with the leg either above or below the knee, usually just below. A bad speedy-cut is an unsoundness, as it is liable to cause an accident of a serious character, the pain inflicted sometimes causing the animal to fall. An abrasion or cut found on the leg in this position is an extremely difficult thing to get rid of, as the horse, directly he is set going, does the same thing again. The horn of the foot of the opposite leg must be kept well cut down, and the shoe placed as much underneath the crust as possible.

From the fetlock the examination is continued down the pastern, viz., that portion of the limb running from the fetlock to the coronet, and here the condition of both the extensor and flexor tendons should be noted. Having done this, the hand should be carefully passed round the front of the coronet in search of a bony enlargement, which if present is termed a

Ring-bone; and if one should be found, the animal should not be purchased, ring-bone being the cause of a very obstinate form of lameness 
which is well-nigh incurable. Cross-firing and blistering occasionally set matters right, but usually the lameness returns again. Ring-bone is present much more frequently in the hind extremities than the fore. From the front of the coronet the fingers are run round to the sides, carefully manipulating the parts here with pressure, to determine if side-bones are present.

Overreach.-In examining the coronet, look carefully for an overreach, which is a tread upon the back part of the coronet of the fore-foot from the shoe of the hind-foot.

Tread. - Treads are abrasions or wounds caused by the treading of one foot on to the coronet of the other. These are frequently the cause of lameness in a horse when bad, but on healing them up they give no more trouble as a rule, unless the parts are badly injured, forming a quittor, and are therefore in themselves scarcely to be considered as an unsoundness. If the tread is a bad one, and a quittor has been formed, then, as a rule, a long time elapses before the animal becomes sound again in his action. 
Quittor.-A quittor is a sinus or long penetrating wound, often going deeply into the structure beneath, and of course, when anything like this is present, the horse should be let alone and not purchased, even if he goes fairly sound, as an animal so affected sometimes will do. A quittor is a great unsoundness, as has been pointed out, usually giving a considerable amount of trouble in healing up.

Side-bone.-A side-bone is an ossification of a cartilage (the lateral laminal) situated at the posterior part of the side of the coronet, and can be easily detected, for if ossification has taken place the parts affected are hard, and do not give to the fingers when pressure is applied. A horse with a side-bone is considered a very unsound animal, for side-bone causes lameness of a very persistent character in the great majority of cases. And very little can be done for the relief of the horse, deep firing and blistering being usually resorted to, but with indifferent success; and the ossified parts have been cut away with a like result. The best form of treatment I know of is that which was first 
adopted some years ago by the late Professor Sewell, of the Royal Veterinary College-viz., to unnerve the horse. The parts then being deprived of feeling or sensation, the pain of course no longer exists, and the animal consequently goes sound. After determining whether side-bones are present or not, and looking to see if the heel is cracked, we pass on to the foot.

The Foot.-Here great care must be used, for if the horse has not a sound foot he is absolutely worthless for work. The hand should be slowly and carefully passed round the horn, especially noting whether there is any heat present; for if the foot is hot something must be wrong within it, probably inflammation of the sensitive lamince (laminitis).

Laminitis. - Should there be a number of rings round the horn, you may be sure laminitis is present, and of a chronic nature, when the horse should of course not be purchased.

There are often present on the horn of the feet of young horses a number of rings called grass rings; these arise from the horse being out in wet paddocks, and if one is not very 
careful these rings may be mistaken for those due to laminitis. But the fact of the horse being young, and the absence of any heat in the foot reveals their true character.

Seedy-toe.-In continuing the examination of the foot, it is a good plan to take a heavy coin out of the pocket, such as a half-crown, and tap the horn all round, but more especially at the toe and sides, to see if the parts sound hollow here. If, on percussion, a hollow sound is emitted at the toe, you will probably, on further searching the part, find that a seedy-toe is present, and this also may be frequently detected by the amateur by the presence of a crumbling or seedy condition of the horn of the sole at the toe. Seedy-toes are of course an unsoundness, but they are not incurable. They are usually amenable to a simple treatment, which consists of paring away with a knife the parts affected, and thereby letting a healthy horny growth take its place.

False Qucurter.-If, on tapping the sides of the hoof, a hollow condition is found to be present, you may be pretty sure that you have a separa- 
tion of the horn there, this condition being known as false quarter. Should it extend over any large surface, the horse would probably fall lame before long. The treatment is a tiresome one, necessitating the horn being all cut away from the affected part, the new horn taking a considerable time to grow right down. Horses affected with false quarter should be avoided. False quarter is a bad unsoundness.

Sandcrack.-In examining the foot, great care should be taken in the search for sandcracks.

A sandcrack is a fissure or slit in the horn, and, commencing at the coronet, it may extend down only a slight distance, or right down to the bottom of the crust. A sanderack is an unsoundness, as it frequently causes lameness, and when once lame from this cause, it is difficult to get the animal sound again. A sanderack may make its appearance in the foot at any moment, from a horse slipping or making a false step.

Dropped Soles. - The foot should now be picked up, and the sole and frog carefully looked 
over. Should the sole bulge outwards, you may be sure that at some time the foot has been affected with fever (laminitis), and this renders the horse unsound. Besides, he would probably have other attacks of this complaint. Therefore, even if, on having the animal trotted, he is found to go sound, it is best to leave him alone and not purchase him. A horse that has a bulging out of the soles of the feet is said to be affected with dropped soles, and this is brought about by the loosening of the tissues, and the consequent undue pressure downwards of the bones within the horny box, the toe of the pedal bone pressing down the sole of the foot beneath it.

Corns. - The examination of the sole of the foot should still be continued with a view of detecting corns, and these, if present, usually make their appearance on the inside of the posterior part of the sole, close up to the crust or wall of the foot; but corns, unless they are bad, cannot usually be detected without the aid of a drawing-knife to search for them. Corns are, of course, an unsoundness, and some horses are very much troubled by them, as they are 
often very difficult to get rid of, frequently festering; and causing the animal to go badly lame. A veterinary surgeon, of course, always casts a horse as unsound that is badly affected with corns; but, on the other hand, if they are not bad ones, and the animal only required to do slow work, especially if the work lies on soft ground, as on a farm, a horse may be purchased, for under these conditions, and if the shoeing is looked to and carefully done, the corns may ultimately disappear altogether. A small corn is often found to be present on examination, and may have been caused, perhaps, by an ill-fitting shoe. If it is well cut out and the shoe altered, it will probably never make its reappearance. Stout leather covering the sole, with plenty of tow placed between to form a pad, is a very good thing indeed to have horses affected with corns shod with, as it lessens the jar or concussion very considerably.

The Frog. - The frog is the next thing to be examined. A sound, healthy frog is a great boon to a horse, as it forms a natural pad to the foot, breaking and taking away a considerable 
portion of the concussion or jar as the horse brings his foot to the ground. A ragged, badly developed, thrushy frog is to be avoided, for here the jar to the foot is not lessened, as it was intended it should be by Nature; and the consequence is the horse is prone to all the ills of concussion, such as laminitis, or fever, in the feet, ring-bones, side-bones, sanderacks, etc.

The examination of the fore-limb being now concluded, we proceed to the withers and back. 


\section{CHAPTER II.}

\section{THE WITHERS, BACK AND GIRTH.}

Is proceeding with the examination of the horse, the hand should be passed over the withers with pressure, in a careful search for sores and fistulas, caused by ill-fitting saddles and pads; and should a bad sore be present, a veterinary surgeon always casts the animal. It is best not to purchase such a horse, for a deal of time and trouble is required to heal a fistula up, and what appears at times not a very bad sore often turns to fistula, and when this is present, and the bone becomes involved, it is a very serious matter.

After examining the withers carefully, pass the hand along the back, pressing as you go along, for should at any time the horse have received any injury to his back, and there may be nothing to see outwardly, he will probably 
flinch on pressure being brought to bear near the seat of injury. If the horse gives way on being pressed on his back in the region of the spine, and more especially across the loins, he should be made to move backwards and turned round sharply from side to side, when the extent of the injury may be judged according as to how he acquits himself. If the injury be a fairly bad one, the animal would not be able to move backwards at all without evincing a good deal of pain, and this also applies to the morement round, and from one side to the other. A horse that is affected like this, and, in vulgar language, said to have 'kinked' his back, is absolutely useless, although to all appearances he may trot on in a forward direction all right. If he has a weight behind him, and it is necessary to pull up sharply whilst driving, he cannot stop the vehicle; and for riding purposes he is no good, as he cannot stand any weight upon his back.

From the back, the hand is passed over the croup and on to the dock, and it is always best to take hold of the dock and move it on one side, looking beneath it to see that all is in 
order there. The precaution should always be taken of looking underneath the girth of the horse and between his thighs, as at times some very large warts, and often a large number of them, may be detected.

Warts, if they are large and numerous, are very troublesome things to deal with. They are very unsightly, and should they be placed between the thighs, where friction takes place, they bleed and become very tender. I have often seen horses badly affected in this way go quite lame in consequence, therefore I would never advise anyone to purchase a horse, if it is required for fast work, that is affected with warts under the thighs, for even if taken out they often make their appearance again. 


\section{CHAPTER III.}

THE HIND-LEG.

From the dock the hand is passed down the quarter and from there to the stifle-joint.

Stifle-joint.-Notes should be taken of the condition $_{, 3}$,f this joint in passing, and enlargements here looked for; but, as a rule, one does not find horses suffering much from diseases of the stifle-joint luxation, or dislocation of the patella, a small bone that is situated in front of the joint being the chief trouble, and if this has occurred more than once, as it frequently does if it takes place at all, a thickening or an enlargement of the parts is usually met with.

From the stifle-joint the examination is continued down the gaskin and thighs until the hock is reached, carefully noting when going over the large tendons (the gastrocnemii), just 
above the hock, that they are not enlarged, as they are occasionally found to be; but should they be enlarged, and the horse goes lame, have nothing to do with the animal, for lameness caused by a sprained condition of these tendons or their sheath is very difficult to deal with, and is as a rule recurrent.

The hand is now passed carefully over the back of the hock, searching for the presence of curb.

Curb.-Curb is the name given to a sprained condition of a ligament that runs down the back of the hock (calcaneo cuboid ligament). Curb is, of course, an unsoundness, and in its early stages often causes lameness; but when once the inflammatory stage is passed, and the ligament becomes callous, lameness from curb is not frequent, and many horsemen, when the horse is of any age, do not bother about it. For my own part, I very much dislike a curb, especially in two classes of horses, viz., the hunter and the large carriage-horse, for in the work required of both these animals a considerable amount of strain is put upon this already sprained liga- 
ment, which is thus apt to break down altogether. Firing is resorted to, with the idea of bracing or tightening up and strengthening the part, this treatment being, as a rule, very effective.

From the back, the hand is now brought to the inside of the hock, the sect of spavins.

Spavins.-There are three kinds of spavins, viz., (1) the bone-spavin, (2) the bog-spavin; and (3) the blood-spavin.

Bone-sparin. - The first, or bone-sparin, is the most common and important of the three, and is an exostosis, or bony tumour, at the lower and inner part of the hock.

Bone-spavin is a common cause of lameness amongst horses, and one of the worst kind, therefore the examination of the hock should be carefully made in search of it. In its early stages it at times takes all the skill of the professional to detect its presence; but when it is fairly developed, and the parts carefully examined, not only by the hand, but by comparing both hocks one with the other as the animal stands quietly and with both hind-legs together, not 
much difficulty should be experienced in detecting it.

A horse with a bone-spavin should be cast, and not purchased on any account, if the animal is required for fast work, or even for any hard work at all, as the bones of the joint being cemented together, as it were, by the bony matter which is thrown out, the animal is almost sure to go lame; the lameness being of a very troublesome character, not much can be done for it. The only cure for these bony formations is blistering, or firing and blistering, and this treatment is far from being always successful.

Bog-spavin.-Bog-spavin is a fluctuating, tense swelling situated at the anterior and inner part of the hock, and is due to the presence of a quantity of fluid from various causes, the chief cause being sprain of the capsular ligament of the joint.

If the swelling is hot and inflamed, it denotes that some structural change is going on within the joint, and the horse may go lame; but, as a rule, bog-spavins do not cause lameness unless they are very large. Not much can be done in 
treating bog-spavin; a well-fitting truss put on, and considerable pressure being thus brought to bear on the affected parts, is the best form of treatment.

Blood-spavin.-Blood-spavin is an enlarged and distended condition of a bloodvessel (the vena saphena) which runs down the anterior and inner side of the hock. Blood-spavins are seldom met with, and are not of much importance unless they are of great size, which is rare.

From the seat of spavin the hand is placed on the point of the hock in search of the enlarged condition of the parts here known as capped hock.

Capped Hock.-There are two kinds of capped hock, viz., the synovial and serous. The former is the worst of the two kinds, and is denoted by a bulging out on either side of the cap of the hock, the bulging being prevented from coming backwards by the gastrocnemii tendon, which is situated at the back of the synovial sac or bursa, and therefore holds it down. Synovial capped hock frequently causes lameness, and is a source of great unsoundness. 
The more common or serous form of capped hock is simply an abscess, and is usually caused by the parts becoming contused from the animal kicking in its stable. They are not a source of lameness as a rule, unless they become very large. They are unsightly, and usually brand the animal as a kicker - at least in the stable.

Thoroughpin. - Search is next made for thoroughpin, which is a bursal enlargement, or swelling at the upper and back part of the hock laterally. It is usually caused by dropsy of the sheath of the flexor pedis perforans tendon, or disease of that tendon itself. The fluid which is contained in the swelling may be forced through by pressure with the hand from side to side of the hock, hence the term 'thoroughpin.'

Thoroughpin causes lameness, but my experience is that it does not do so often, unless it is very large.

From the hock the examination is continued down the back or flexor tendons, and what has already been said about these tendons in the fore-limb holds good in those of the hind-leg. Splints are very rare behind, but one does 
occasionally come across them. Wind-galls are frequently found affecting the fetlock of the hind-leg.

Ring-bone is much more frequent in the hind than in the fore extremities, whilst sandcrack usually makes its appearance in the front of the foot, instead of at the side, as is more often the case in the fore-feet. Corns are very seldom seen. Side-bones very rarely occur in the hindfeet; they have been known, but are extremely uncommon.

With the conclusion of the examination of the hind-leg concludes the examination of the horse as he stands. This being so, we must now have the animal run up and down the place where the examination is being made, in order to test whether his action is sound or not. 


\section{CHAPTER IV.}

\section{ACTION.}

LET the groom run the horse at a nice slow trot, letting the animal have its head, and allowing plenty of rein for this purpose. The man should run straight on, dropping his hand the while. This enables the examiner to see the horse trot fairly and naturally. Whilst the horse is trotting away from one in this slow way, the action of the hind-legs can be carefully noted; the movement of each joint should be carefully watched, especially that of the hocks and fetlocks. Note should be taken as to whether the movements of these joints are free or stiff, and whether the horse drops on one of the legs. And it is always to be remembered that, if a horse is lame on the near or left leg, he will drop on the off or right leg, this being caused by the weight being put 
upon that limb, in order to relieve the pain occasioned by the using of the lame leg. Many amateurs, seeing a horse drop on one leg, immediately conclude that the animal is lame in the leg it drops upon, but of course, after a little reflection, it is easily seen that this could not be the case.

Brushing.-Care should be taken in noting whether the fetlocks brush as the horse trots along away from you, for brushing, or the knocking of one fetlock against the other, is a great evil, and a difficult one to eradicate. Some horses habitually do this, and all the methods of shoeing that can be thought of are at times of no avail, and there is no help for it but to always let the horse wear a boot, which is, of course, extremely unsightly, to say the least of it. Young and green horses are frequently addicted to this irregularity of gait, as are also weak, weedy, and leggy animals. A horse that brushes badly is an unsound animal, and should be cast as such, for the continual knocking of the fetlocks injures these joints to such an extent that bony matter is often thrown out, and an enlarged 
joint is not the only consequence, but a permanent stiffness of the joint is also often apparent, and at times the bone becomes badly injured.

Cutting.-Cutting is caused by the shoe attached to one foot wounding the fetlock of the opposite leg. This can, as a rule, be stopped by the shoe being well tapered off, or feathered and placed as far underneath as possible.

Springhalt.-Stringhalt, or springhalt, is a nervous complaint, and consists of the sudden jerking upwards and forwards of the hind-limb as the horse moves along. This complaint, if it is present to any marked extent, is very tiring to the horse, and wears him down in a journey, and is therefore considered by most veterinary surgeons as an unsoundness; an animal so affected should be avoided, unless it is only required to do slow work, such as carting, etc.

Some horses go very wide behind, but although this is unsightly, it does not inconvenience them at all, and therefore no note need be taken of it. I have frequently noticed that fast-trotting horses are often subject to this manner of gait, especially the horse that is a runner, viz., one that moves 
both near-side limbs together, and both off-side limbs together. It should be noted that overreaching does not take place. After the action of the hind-legs has been thoroughly tested, the action of the fore limbs now engages one's attention.

The horse is gently trotted towards the examiner, and here, after determining whether the animal is lame, or whether he has the free use of his joints, notice should be taken as to whether he is inclined to speedy-cut or brushing.

Some horses have a peculiarity of gait termed dishing, which consists of throwing or turning the feet outwards as the flexors are brought into use, giving the action a very unsightly appearance if present to any marked degree.

Tery high knee action looks rery pretty for park work or the show-ring, where the horses are required to make a show, but for ordinary purposes it is fatal to the soundness of the feet, the continued concussion consequent upon it invariably producing laminitis, or even, what is much worse, naricular disease. Corns, side-bones, and badly-bruised soles are also frequently present 
in horses with high action. I remember examining a horse for a gentleman, the price of the animal being some $£ 350$, which had the most extravagant action in front, and although the horse apparently went sound, the feet had every disease that a horse's foot could possibly be afflicted with, and had it been worked for a week would have gone irretrievably lame. Sound long-striding action, the leg being well extended from the shoulder, is the best for all purposes.

Whilst examining the action of the fore extremities, speedy-cutting should be carefully watched for. Lameness from speedy-cutting is very difficult to prevent if the animal goes very close in front. The only plan is to place the shoes as far under the crust of the horn as possible, carefully rasping away as much horn as is consistent with safety; and if this does not prevent it, a boot must be worn, which for town work or good-looking and showy horses is very unsightly indeed. Such a horse had far better be avoided and left alone.

What has been said about brushing behind applies to the front-legs, but brushing is far more 
frequent behind than in front. To carefully satisfy one's self as to the soundness of the action of the horse under examination, the animal should be trotted up and down a distance of, say, some fifty yards at least twice, or even three times, should there be any doubt upon the matter ; and should it be a stone-paved road that the horse is being run upon, so much the better, for the test is naturally more severe, the concussion being greater, and therefore much more likely to bring out any weakness that may be present, and which would probably not be apparent if the animal were being tested on a soft road. After having fully tested the action of the horse and determined whether it is sound or unsound, or that there are peculiarities of gait present that warrant the horse being cast, one proceeds to the examination of the animal as to the soundness of its wind. 


\section{CHAPTER V.}

\section{THE EXAMINATION AS TO SOUNDNESS OF THE RESPIRATORY APPARATUS.}

There are many affections interfering with the proper working of the respiratory apparatus of the horse, and rendering the animal unsound in its wind, viz. :

Broken wind.

Roaring.

Whistling.

Grunting.

High blowing.

Chronic cough.

To test a horse for its wind, the animal should either be galloped at a fast pace, or, if it is a heavy harness horse, put in harness and driven, when, the respiratory apparatus having a strain 
upon it in its working, any defects that may be present make themselves apparent.

In my opinion, to stand a horse against a wall and strike at it with a stick or the fist is no test at all, for a nervous and excitable animal is by this mode of procedure worked up to such a pitch that anything it does cannot be taken as a true indication of its normal condition. Nothing can be more censured or deprecated than the severe pressing of the cartilages of the throat that some people practise in endeavouring to make the horse cough, and I have no doubt that many a horse that has been standing in a sale-yard for a couple of days prior to sale, that was perfectly sound before being sent there, has developed roaring, though perhaps much oftener whistling, by injury done to the cartilages of the throat by severe pressure being repeatedly applied by different persons making the test. As stated above, to properly test a horse's wind, the animal should be galloped, but if it is a heavy harness horse, it should be put in harness and driven as fast as is expedient.

In the case of heavy draught horses, when 
practicable, put the animal in harness with a heavy load behind it. This is all that is required. If, as in the case of a hunter, the horse is galloped, listen intently as the animal passes by you for any abnormal sounds that may be emitted, and in roaring, as the respiratory organs are gradually brought to do their utmost, a deep, rough, rushing noise is heard, and the animal shows signs of difficulty in respiration. If a whistling noise is made, the animal is termed a 'whistler.' After some few minutes' (about five) galloping, the horse is brought to a standstill, and the examiner stands up to its head and listens to the breathing, when, if either of these affections is present in a slight degree, too slight, perhaps, to be detected as the animal is in motion, it can be readily heard when listening quietly at the horse's head after he has been pulled up.

In the case of broken wind proper, there is no noise made, but the animal respires very rapidly, and the abdominal muscles are brought into play to assist in the expirction of air, the flanks heaving heavily-like a bellows, in fact.

Broken Wind.-The condition known as broken 
wind is due at times to asthma, but mostly to emphysema of the lungs, which is an infiltration of air into the interlobular cellular tissues of the lungs.

Broken wind is a bad unsoundness, and a horse required for fast work so affected is useless. For slow work, unless required to draw heavy loads, it does not matter so much, but no one in purchasing a horse should buy a broken-winded animal if possible. A horse that is brokenwinded, if worked much, often goes all to pieces in a very short space of time.

Roaring.-Roaring is due to the atrophy or wasting away of the muscles (crico-arytenoid) which regulate and control the cartilages forming the upper and left side of the larynx, which is a cartilaginous box forming the beginning of the windpipe. The muscles, being wasted away and the cartilages not being controlled, drop slightly over the aperture of the larynx, and hence the noise which is made during the act of inspircution. Roaring is, of course, an unsoundness; and all horses so affected should be avoided, as they are capable of very little fast exertion. 
Whistling. - Whistling is mostly due to a thickened condition of the mucous membrane lining the air-passages, and a consequent narrowing of these passages. Whistling is an unsoundness, but the horse is capable of more fast work than a roarer.

Grunting.-This is the name given to the noise that is at times made by a horse on being suddenly and unexpectedly struck at either by the fist or with a stick; an animal making such a noise is termed a 'grunter.' The making of the noise may be associated with disease of the throat, or to some abnormal state of the chest; or, on the other hand, it may be caused, and frequently is, by the horse being fat and out of condition. Many a horse that grunts is perfectly sound in his wind, and many a horse that is a bad roarer will not grunt on being tested. Grunting points to a probable unsoundness of the wind, and when a horse makes this noise he should be most carefully exanined in other respects for soundness of wind.

Grunting is considered by many as an unsoundness, but, in my opinion, unjustly so, for if on 
further examination the wind is found to be sound, the making of the noise referred to points to nothing that militates against the usefulness of the animal.

High Blowing.-A high-blower is the name given to a horse that makes a noise by flapping the alæ, or wings, of the nostrils whilst being ridden or driven. Many inexperienced people mistake this noise for roaring; but, on being pushed, the horse often desists, on settling down to his work, from making this noise, whereas if a roarer be pushed to greater exertion, the noise increases. A high-blower is not an unsound animal, the act merely being a habit.

Chronic Cough.-When a persistent cough is present, and from its description leads one to believe that it is chronic in character, the horse should be put down as unsound and avoided.

A chronic cough may denote the presence of disease of the throat or chest, and it is frequently present in broken-winded horses. 


\section{CHAPTER VI.}

\section{THE CONFORMATION OF THE HORSE.}

$I_{N}$ the selection of horses as to purchase, besides being able to judge as to the soundness of the animals, one requires to have some knowledge of their shape or configuration in order that the horses may be well chosen.

The Head.-The head of the horse should be small, especially if the animal is required for riding purposes, as a large and cumbrous head, besides looking ungainly, makes the horse hang heavily on its rider's hands. A small head shows good breeding; a large head denotes the contrary. There should be plenty of width across the forehead, and the muscles covering the head generally should not be too well developed in size; there should be plenty of space between the jawbones, and also from the eyes to the angle of the jaw. 
The forehead should be broad and not too prominent, as prominence here often denotes bad temper; the nostrils should be large and well developed, in order to allow of free respiration, as it must be always remembered that the horse breathes entirely through his nostrils, and not in any degree through his mouth, which should also be of small size.

The Eyes. - The eyes should be large and prominent, and the eyelids thin. Horses with small eyes are often uncertain in temper, and cannot therefore be depended upon.

The ears of a well-bred horse are usually small; they should point forwards and be thin.

Neck.-The neck should be lightly and gracefully curved upon the upper portion, and the muscles here are usually very firm in a horse that is in hard condition. A neck should not be short and thick, but of a fair length.

Withers. - The withers should be fairly well developed and tolerably high, as space is required here for the attachment of the numerous muscles, ligaments, and tendons; besides which consider- 
able leverage is also necessary for these various attachments in controlling the movements of the fore-limb.

A horse with high withers is usually an easy ride; but low withers, generally associated with straight shoulders, are more often than not an indication of the reverse.

The Chest.-The chest should be of good depth and fairly broad, in order that the vital organs placed within may have plenty of scope to perform their functions. Narrow-chested horses are, as a rule, bad stayers; but whilst a fair amount of breadth is very desirable, a very broad-chested horse is, as a rule, an uncomfortable mount, the animal usually having an unsteady, rolling action, but for harness purposes this is, of course, immaterial.

The Shoulders.- Should the horse be required for riding purposes, a thick, heavy and straight shoulder is to be avoided, for an animal so constituted is unfit for riding, as he not only gives the rider an uncomfortable motion, but cannot extend his shoulders and get away well at the canter and gallop. A horse with a shoulder 
such as has just been described is more fitted for harness work.

When the animal is required for riding, the shoulder should be long and cleanly developed, and placed upon the trunk, as it were, in a slanting or oblique manner. With a shoulder such as this, the horse, by being able to extend his fore-limb well, can get away much better at the canter and gallop, and also gives his rider a nice easy feel.

The Arm.-The arm, or that portion of the leg between the elbow-joint and the knee, should be long, whilst plenty of bone should be present, and the muscles upon it well dereloped. The greater the muscular development the better.

The knee should be prominent, and nearly flat in front, whilst it should appear small when viewed from behind. Laterally, it should be wide. A horse should stand quite straight at the knees, and if he stands over at them, a weakened condition of the ligaments and tendons is indicated. The limb below the knee should be flat and broad, and the tendons distinctly defined and tense. The metacarpal or shank 
bone, which is the large bone that extends from the knee to the fetlock, should be short and stout and perfectly straight. It is most important that this bone should be strong, for if it is not so, should the animal be put to hard work, it is almost sure to go wrong-it will become bent, or splints will be thrown out in a very short time. There are two minor bones as well as the large one-one on either side of it-the small metacarpals, which go to make up the bony mass from the knee to the fetlock; but these are unimportant in their usefulness in assisting to support the weight of the body.

Fetlock and Pastern.-The pastern of the well-bred horse should be oblique, not straight, for the slanting position gives to the animal in its gait a springy action, and a lot of concussion is thereby avoided. For riding-horses this is very important, for if the pasterns are almost straight, a deal of concussion is bound to take place when the horse travels at any pace at all. A horse so constructed is very prone to develop side-bones, and to become affected with the various other diseases of the feet. 
The Feet.-In selecting a horse for purchase, it is all-important to see that the animal has good and sound feet. Large flat, splodding feet should always be avoided, as they are prone to disease, and especially to laminitis, or fever. A narrow foot, again, especially one that is narrow at the heels, is a bad-shaped foot for a horse to have, as feet of this shape very often become affected with navicular disease, the worst cause of lameness a horse can be troubled with. A foot that is not uniform in size-viz., one side being larger than the other-is a bad foot, as it shows that some structural change has taken place, which may probably cause lameness at some future date. A foot that is neither too large nor too small in proportion to the horse's size, of a nice round shape, the horn not shelly or brittle or encircled by rings, the soles of a nice clean, compact appearance, slightly arched or concave, with a well-developed frog, is the ideal foot. Both feet should be of the same size, and the horse should stand straight upon the ground, neither turning them out nor inwards. 
The Back.-The best back is a straight back, and one that is not over-long. For speed a certain amount of length is requisite, though for strength a short back is the thing to be most desired. Hollow backs should be avoided, as they are as a rule weak, and the hollowness increases considerably as the animal gets older. Roach-back horses are uneasy to ride, and are unsightly. This term is given to backs which protrude upwards along the centre of the spine, and is caused by an undue prominence and development of the superior parts (superior spinous processes) of the bones of the dorsal vertebræ.

Loins. - The loins should be long and muscular, and well arched in shape, the muscular development being of great importance in this region.

Ribs.-The ribs should be deep and of an oval shape, and be brought well backwards towards the hips, the horse then being said to be well ribbed up.

Hips. - The hips should be fairly wide, but not too much so. In riding-horses, and especially in hunters, they require to be more largely developed than in harness horses, although too 
much breadth of space between them is not desirable.

The Hind-Quarters. - The hind-quarters should be long, round on the outside, and deep, and there should be considerable length from the hip to the hock. This is essential for hunters and ridinghorses generally, the great majority of good jumpers having great length there. There should be considerable length in the continuation of the back from the loins to the tail, and this region should be fairly straight. Short round quarters are undesirable, as also are very drooping quarters, although, of course, exceptions occur to this rule-notably in some classes of hunters. The thighs should be prominent and muscular, the muscles well developed.

The Hock--It is very important when selecting a horse that the hocks should be sound and of good shape, for a great deal of strain is put upon this joint in all classes of horses. The hock should be clearly defined, and have no swelling. whatever upon it, as swellings or enlargements of any kind denote weakness. It should appear wide when looked at from the 
side, be fairly large and prominent, and tolerably well bent. Straight hocks are bad, as they do not assist in lessening the concussion, and consequently often go wrong. The point of the hock should be well developed and prominent, as here a great deal of leverage is required for the tendons of the leg.

The hocks, as the horse is standing squarely and fairly, should neither be too wide apart nor too close to one another, but should be placed straight under the animal's body, and not turn outwards or inwards. For all practical purposes a strong, compact, and fairly large hock is the best, and, as has already been said, it should not be too straight, otherwise you may expect it to become affected with spavin. On the other hand, if too much bent, the probabilities are that curb will make its appearance if the animal be put to hard work. Narrow hocks, also, should be avoided, as being predisposed to spavin and curb. The leg below the hock should be short, and what has been said as to the conformation of the limb below the knee applies equally to the leg below the hock. 
The great metatarsal or cannon bone, which is the bone placed between the hock and fetlock, and which has a small metatarsal bone on either side of it at the posterior part, as in the forelimb, should be perfectly straight, and incline slightly obliquely forward.

The Body.-The body should stand over a good deal of ground, and be long and low. For speed length is very necessary, whilst for staying power and endurance generally we look to breadth.

In casting the eye over the body, note should be taken of the size of the sheath, as horses with a large sheath are usually good ones, whilst the reverse is most frequently the case when the sheath is small.

The Tail.-The tail should be well and firmly set on the body, and be carried away from the quarters. In well-bred horses the hair of the tail is usually fine and silky, whilst in the underbred horse it is coarse and inclined to be curly, and, as a rule, clings to the quarters in a manner that is anything but ornamental. 



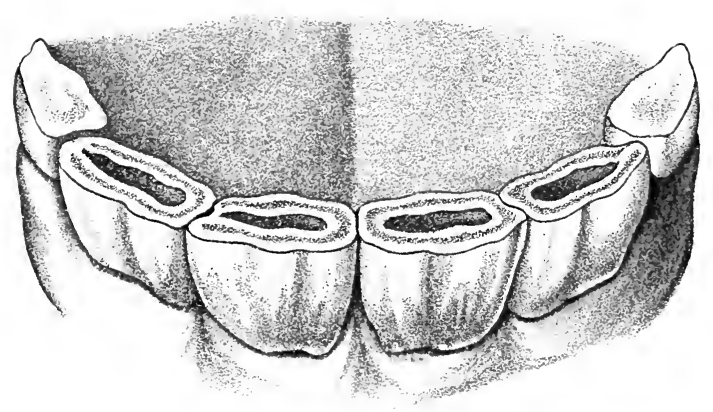

\section{Years 0ld.}

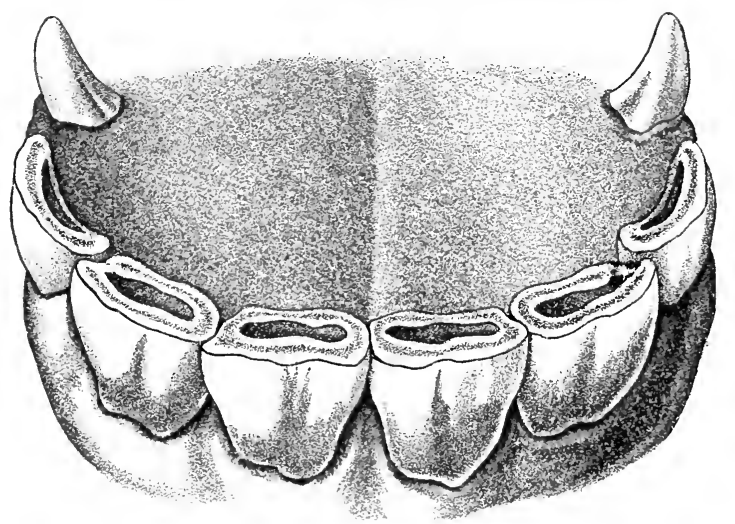

\section{YeARs Old.}

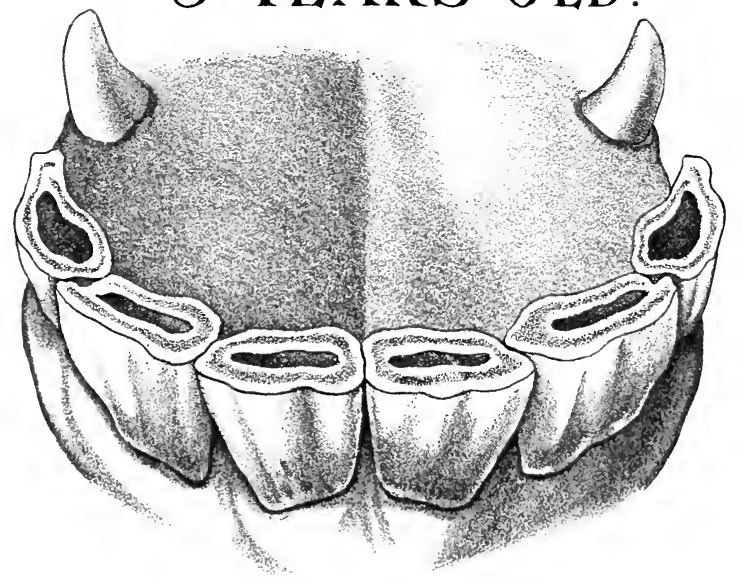

6 Years Old . 
AGE OF THE HORSE AS SHOWN BY THE TEETH 6I

Showing the tables of the teeth at-

\section{FOUR YEARS OLD.}

\section{FIVE YEARS OLD.}

\section{SIX YEARS OLD.}




\section{CHAPTER VII.}

\section{THE AGE OF THE HORSE AS SHOWN BY THE TEETH.}

THE examination of the teeth of the horse is a simple matter, but perhaps a few remarks upon the way to go about it will not be out of place to the uninitiated.

To inspect the incisors, all that is required is to separate the lips; but some horses are naturally shy when their mouths are touched by strangers. These animals should be handled with the greatest carefulness and caution. If restiveness is shown to any extent, let the groom in charge, who probably knows the horse, part the lips, and the examiner can then quietly and without trouble note the appearance of the teeth. If the groom be a stranger to the horse, and the animal seems inclined to be nervous, the neck should be patted and the face and nose 
stroked, when, in nine cases out of ten, the horse will quieten down and allow you to handle him as you require.

When a very careful examination of the incisors is required, it is best to take hold of the tongue and draw it partially out of the mouth, when the whole of their arrangement can be easily seen.

When it is necessary to inspect the molars, it is best done with the aid of the balling-iron. The instrument inserted into the mouth, and the tongue carefully drawn out, the molars and their arrangement can be seen with the greatest ease. With a restless horse, who fights against the iron being placed into his mouth, a twitch acts as an extremely good sedative; but this can, as a rule, be dispensed with if the horse be handled kindly, and at the same time with a certain amount of firmness.

\section{Parts of the Teeth.}

A tooth is divided into three parts-viz., crown, fang, and neck. The crown is that portion that projects into the mouth above the 
gum ; the fang is that part which is hidden in the jaw; and the neck is the portion which unites the crown and fang and is surrounded by the gum.

The upper or superior part of the crown is termed the table, and comes into apposition with the tooth of the opposite jaw when the mouth is closed. Through the tooth, to a greater or lesser degree, and commencing at the bottom of the fang, runs a cavity termed the 'pulp cavity,' or sac, in which is contained the pulp, the pulp being composed of bloodvessels and nerves, with a certain amount of connective tissue.

Three different substances enter into the composition of a tooth: firstly, the dentine, or ivory; secondly, the enamel; and thirdly, the crusta petrosa.

The dentine, or ivory, forms the greater bulk of the tooth, and is centrally situated. On the outside of that part of the dentine which projects above the gum is situated the enamel, a white, glistening, extremely hard substancethe hardest portion, in fact, of a tooth. The 
outside of the enamel is covered by a very thin calcified substance termed the cuticle of the enamel.

Surrounding that portion of the dentine which is situated beneath the level of the gum is the crusta petrosa, or cement, which is composed of true bone.

At the neck the crusta petrosa and enamel come in contact, the enamel increasing in thickness towards the crown of the tooth, and the crusta petrosa towards the end or root of the fang.

At the superior part or table of an incisor tooth is noticed a cavity of variable depth, called the infundibulum. The infundibula are deeper in the permanent teeth than in the temporary, are greater in the upper jaws than in the lower, are present in the superior or upper molars, but not in the inferior. The inferior molars have no infundibula, but only grooves and fissures.

In structure dentine, which closely resembles bone in its chemical composition, is seen under the microscope to be finely channelled by a large number of delicate tubes, which communicate with the pulp cavity by their inner ends, and by 
their outer come in contact with the under surface of the enamel, and cement and sometimes penetrate them.

The enamel is the hardest portion of the tooth, and chemically is made up of the same elements that go to form dentine and bone. In structure, when examined under the microscope, enanel is found to be composed of fine hexagonal fibres, which are placed on end to the surface of the dentine, and fit into minute cavities on its surface. As has been already stated, the enamel is covered on its outer surface by a thin membrane, which is calcified, and termed the cuticle of the enamel.

\section{Arrangemext of the Teeth.}

The horse possesses forty teeth-viz., twelve incisors, four tushes, and twenty-four molars.

The incisors are those which are situated in front of the mouth, and are classed in pairs, being usually cut and developed in that way. The middle or centre two are termed the centre incisors, the next to them the lateral, and the two most backward ones the corner incisors. 
The tushes are placed two in the lower jaw and two in the upper, and are situated in the space between the incisors and molars. The tushes are only completely developed in the male, no sign of them whatever frequently being noticed in the mare.

The molars are arranged six in each side of the upper jaw and six in each side of the lower jaw, and are spoken of as the first, second, third, fourth, fifth, and sixth, counting from the front.

Nature has provided the horse with two sets of teeth. The first, which are small in comparison with the others, are termed the milk or temporary teeth. They are twenty-four in number-six incisors in each jaw, and three molars on each side of the upper and lower jaw.

The molars, which are the first, second, and third, begin to be shed at two and a half years, and are all absent between the third and fourth years.

The milk incisors are much smaller than the permanent ones, and are considerably whiter in colour. The crown is much smaller, and the neck is well developed. 
The temporary molars do not differ so very much from the permanent ones, though the table of the former is somewhat narrower than that of the latter.

\section{The Wolf-teeth or Eye-teeth and Tushes.}

Besides the temporary teeth already mentioned, there are two small nodules of tooth-like structure situated immediately in front of the first molars of the upper jaw (being but very rarely seen in the lower jaw), one on either side. They are of no importance, and are usually shed with the first molars; but in isolated cases they are not shed so early, and remain some considerable time after the arrival of all the permanent teeth. The wolf-teeth are generally present, or indicated at birth.

The tushes, as a rule, make their appearance between the fourth and fifth year. Sometimes they are cut in a very irregular manner, and come up between the second and third year, and occasionally as late as the eighth year; but, generally speaking, they are first seen just 
piercing the gum between the fourth and fifth year.

Birth.-At birth there are usually to be found three molar teeth on either side of each jaw, and possibly two front incisors. These latter for the time being are situated in a rather lateral position, but in most cases it is a fortnight or three weeks before the incisors appear.

Six Weeks. - At six weeks two more incisors generally make their appearance, and those that first came up have become much more centrally situated.

Six Months. - At six months the incisors that are up have obtained the position they will in future occupy, and if the gum be carefully examined, signs will be noticed of the cutting of the corner incisors.

Nine Months. - At nine months old the corner temporary incisors are well up, but their edges do not come into apposition. 


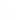



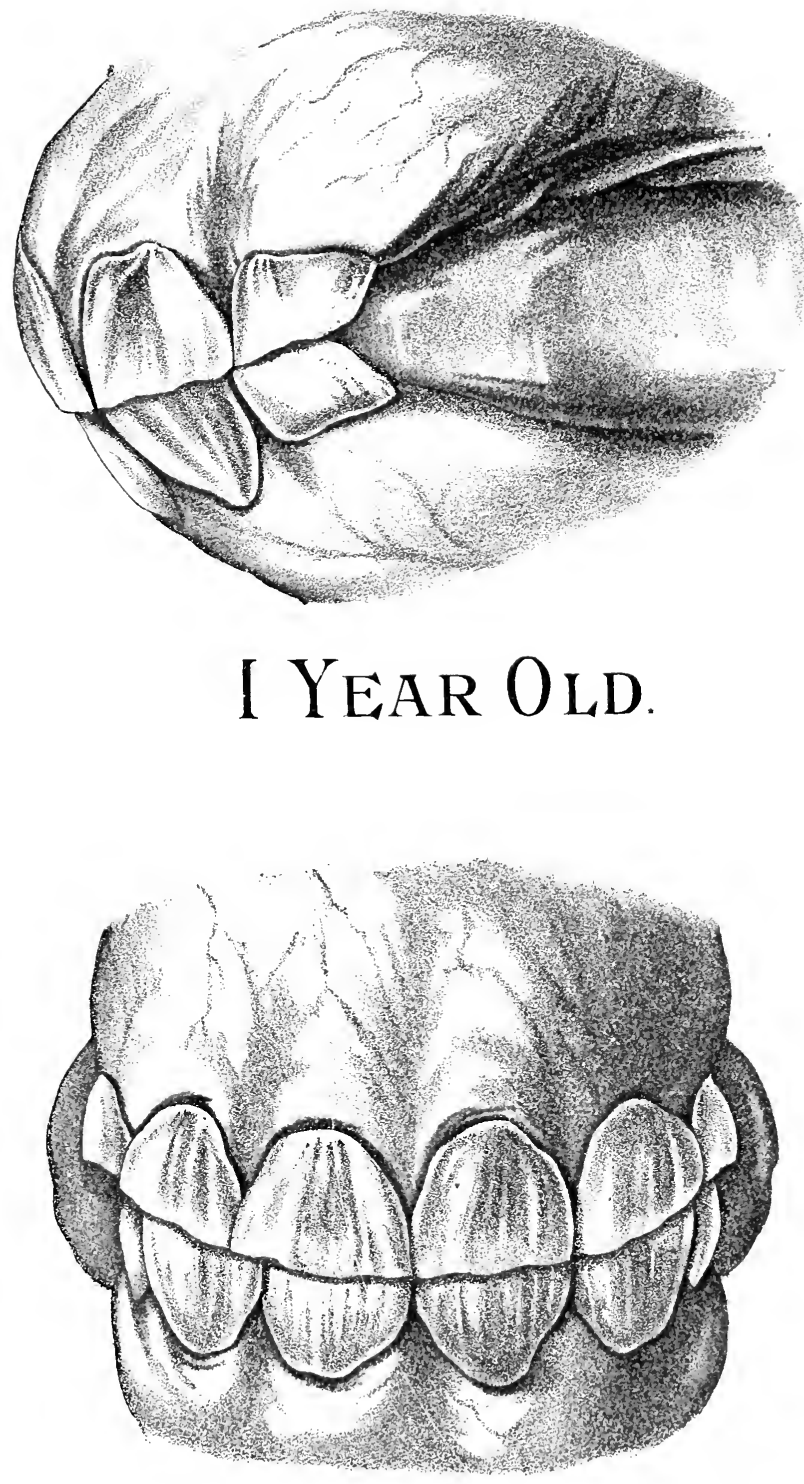

\section{YeARS OLD.}




\section{ONE YEAR OLD.}

All temporary teeth up and their edges meeting.

\section{TWO YEARS OLD.}

A full mouth of temporary incisors, all showing a good deal of wear. 


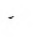


One Year.-At one year all the milk-teeth are up and meet. The fourth molars, which are permanent, now show themselves, and therefore the one-year-old horse or yearling has twenty-eight teeth altogether — viz., sixteen molars and twelve incisors.

The accompanying illustration of a yearling's mouth may be taken as absolutely correct, as a large number of mouths were inspected and examined to verify the drawing.

In passing, I may say that I am greatly indebted to Mr. A. Clarke, artist, 42A, Bow Lane, London, E.C., who took the greatest possible pains in drawing the illustrations accompanying this chapter.

One Year and Six Months. - At this age the fifth molars make their appearance, one on either side of each jaw. The incisors show some wear, and the infundibula commence to become obliterated.

Two Years. - At two years old the milk incisors, all of which are still present, show a 
good deal of wear, and the infundibula have practically disappeared. The fifth molars are right up, and their edges are in apposition. The two-year-old mouth to the non-expert bears a great resemblance to that of the five-year-old one, as all the temporary incisors, besides being present, have grown fairly large and stronglooking; but a careful examination of the teeth, along with the general youthful appearance of the animal, will prevent this mistake from being made.

Three Years. - At three years old the centre permanent or horse teeth are well up and developed, being cut at about two and a half years. They are readily distinguished from the temporary or milk-teeth by their shape and size, and the colour, which is darker.

The three-year-old mouth is very easily recognised, as the new central teeth show such a great contrast with the milk-teeth that still remain. In being shed it is the upper central incisors that are first removed.

At three years old the first and second per- 



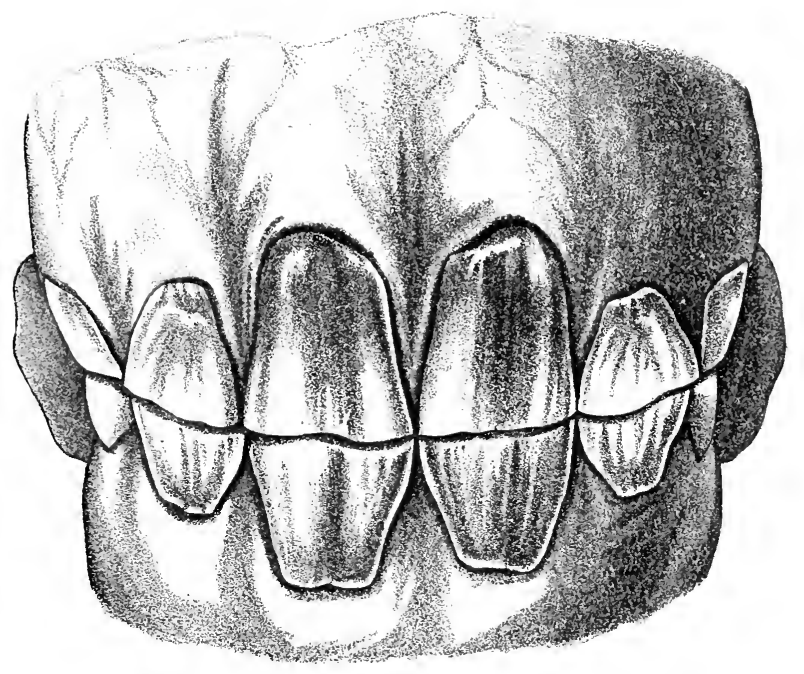

\section{Years 0LD.}

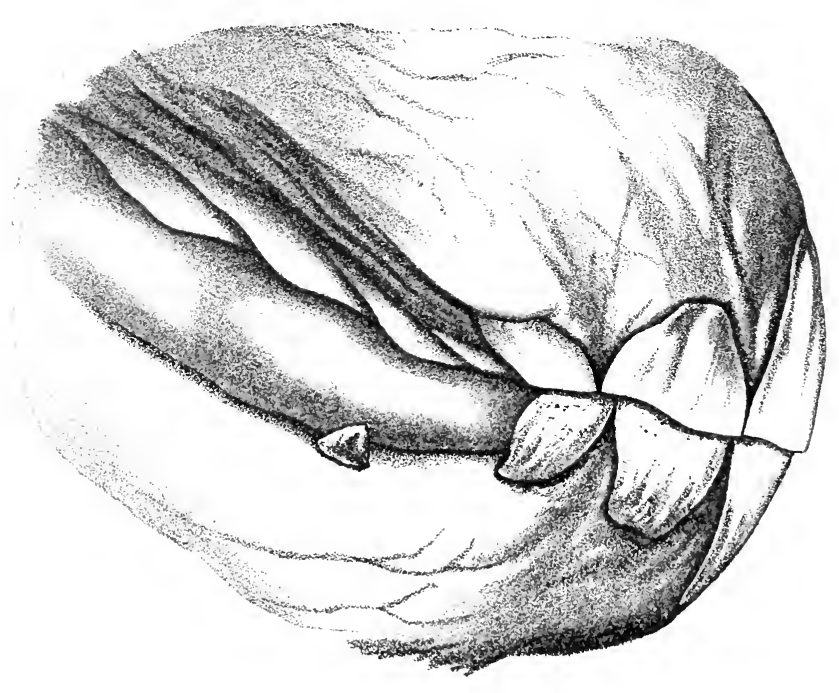

\section{Years OfF.




\section{THREE YEARS OLD.}

The centre permanent teeth well up. These are distinguished by their size and shape and colour from the milk-teeth on either side of them.

\section{THREE YEARS OFF, LATERAL VIEW.}

Here the tush may be seen just peeping through the gum. The lateral and corner milk incisors show much wear, and the lower lateral incisor is about to be shed. 

manent molars have made their appearance, generally coming up about two years and nine months, the temporary molars having by that time disappeared, their fangs first becoming absorbed, and their crowns shelling off from those of the oncoming permanent molars. Therefore, at three years old the horse has two central permanent incisors in both the upper and lower jaws, and four permanent molars on each side of either jaw, these being the first and second molars, always counting from the front of the mouth, and the fourth and fifth molar, the fourth, it being remembered, being up at one year and the fifth at two years.

The wolf-teeth are usually shed at about two years and nine months.

The terms 'rising' or 'coming,' when placed before the number of years the horse has been born, as 'coming' or 'rising three' or 'rising four,' means that the animal is not three or four years old yet, but will be in a couple of months or so. And the term 'off' placed after the number of years, as 'three off,' for instance, 
means that the horse has recently passed his third year by three or four months.

Three Years Off.-The tushes at three years off are often seen making their appearance through the gum, and those of the lower jaw first, but no great dependence can be put upon them in assisting to denote the age at this period.

The lateral milk-teeth are shed about the seventh month after the third year, those of the lower jaw going first. The lateral permanent teeth then make their appearance.

Rising Four. - At rising four the whole of the lateral teeth are in the mouth, but their edges do not properly come in apposition, as is depicted in the plate.

Four Years. - At this age the lateral incisors are well up and developed, but the corner milk incisors still remain. The tables of the central incisors show considerable wear, and the infundibula are well defined. Some or the whole of the tushes may be well up also; but no great 


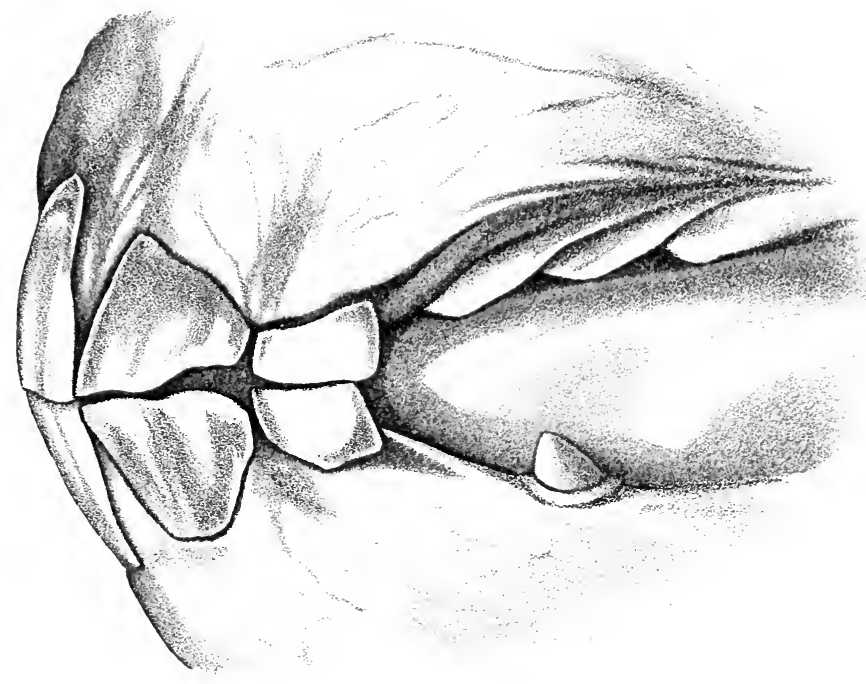

\section{Rising 4 Years.}

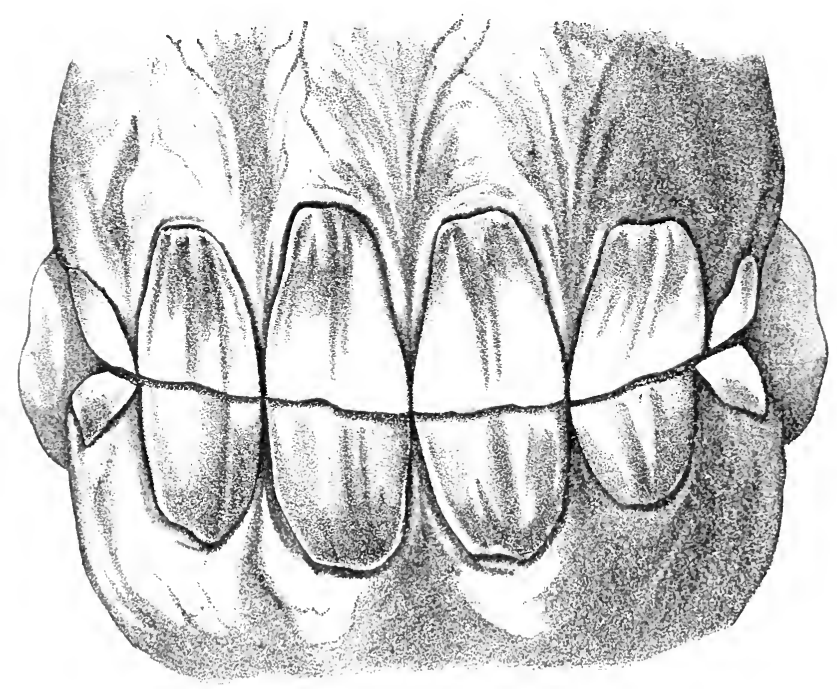

\section{Years Old.}




\section{RISING FOUR YEARS.}

The lateral permanent incisors are well up, but their edges are not in apposition.

\section{FOUR YEARS OLD.}

The lateral or permanent horse teeth well up and their edges meeting, but the corner incisor still present. 


\section{FIVE YEARS OLD.}

A full mouth of permanent incisors, the edges of which are in apposition.

\section{RISING FIVE YEARS.}

All the permanent incisors in the mouth, but the corner incisors not yet meeting. 


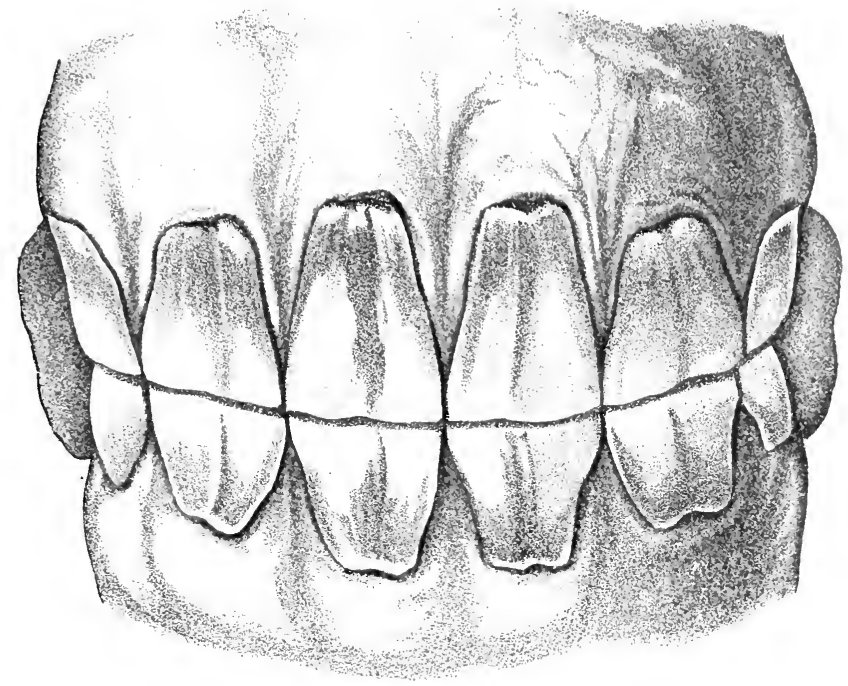

\section{YeARs 0Ld.}

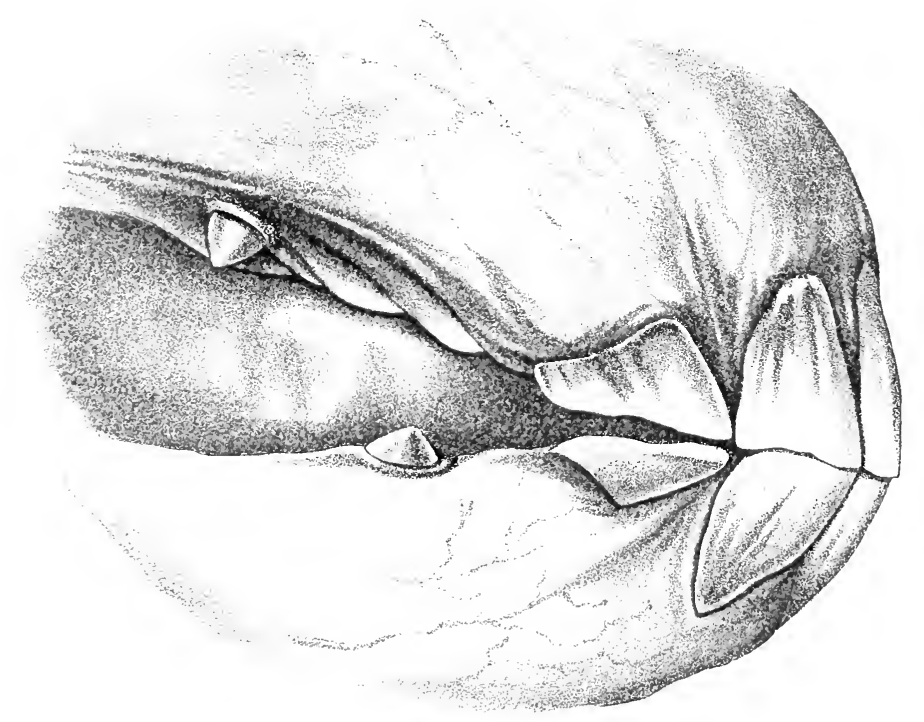

Rising 5 YeARS. 

dependence can be put upon these teeth, as they are not at all regular in their mode of development. The third and sixth molar teeth are well up at four years old, being cut at about three years off, the sixth coming up first.

Rising Five.-At rising five all the permanent or horse teeth are in the mouth; but the corner incisors do not come in apposition, especially at the posterior or back portion of the tooth, as will be seen in the illustration of rising five. At this age the corner incisor has a very shell-like appearance, and the table is not at all developed.

Five Years. - At five years there is a complete and full mouth of permanent incisors, the edges of which all meet; but the tables, however, are not yet properly formed, which is, of course, most noticeable in the corner incisor, this tooth being the last one to come up.

Five Years Off.-At this age the corner incisors show but very little wear, and are some- 
what rounded at their posterior margins. The infundibula of the central teeth are becoming shallow, and in some cases this is very marked, the tables showing a certain amount of wear. The tables of the lateral incisors are quite formed, and their infundibula are also getting somewhat shallow, with well-defined margins.

Six Years. - The corner incisors at this age are firmly set in the jaws, and their edges begin to look uneven. The tooth (corner incisor) has a somewhat square appearance, and the roundness of the posterior margin has all but disappeared. The table of the corner teeth is not yet quite fully formed, the infundibula not being surrounded by a level surface.

Six Years Off.-At this age the table of the corner incisor is very fairly developed. The tushes are well set up.

Seven Years Off.-At this age the corner incisors show a considerable amount of wear, and the infundibula of the lateral incisors are 


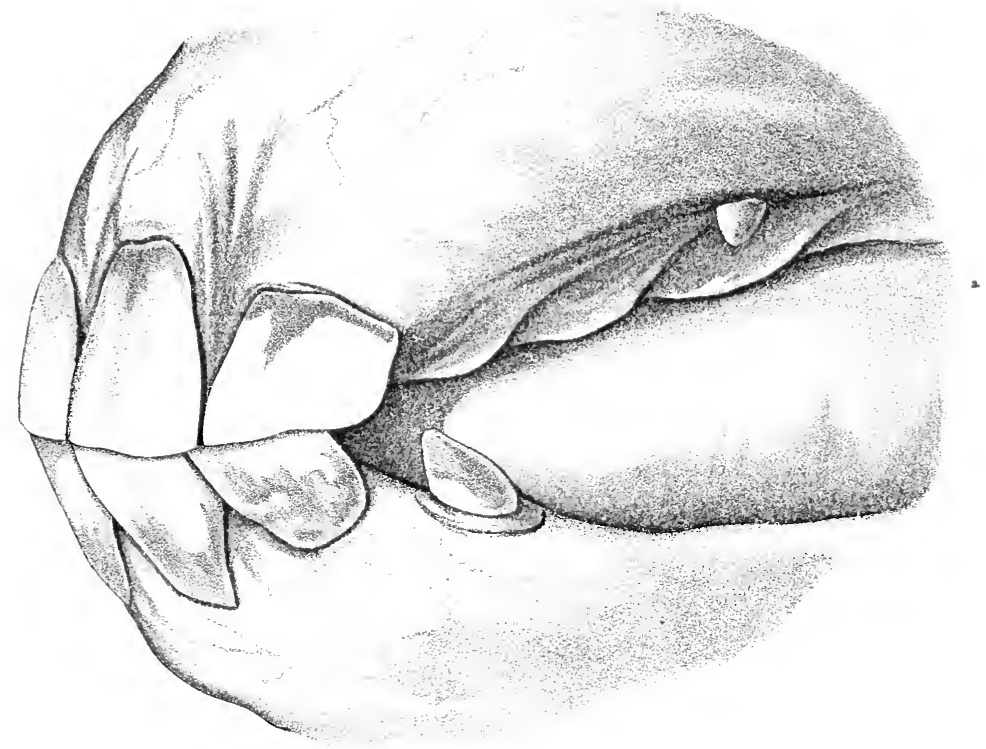

\section{YEARS OFF.}

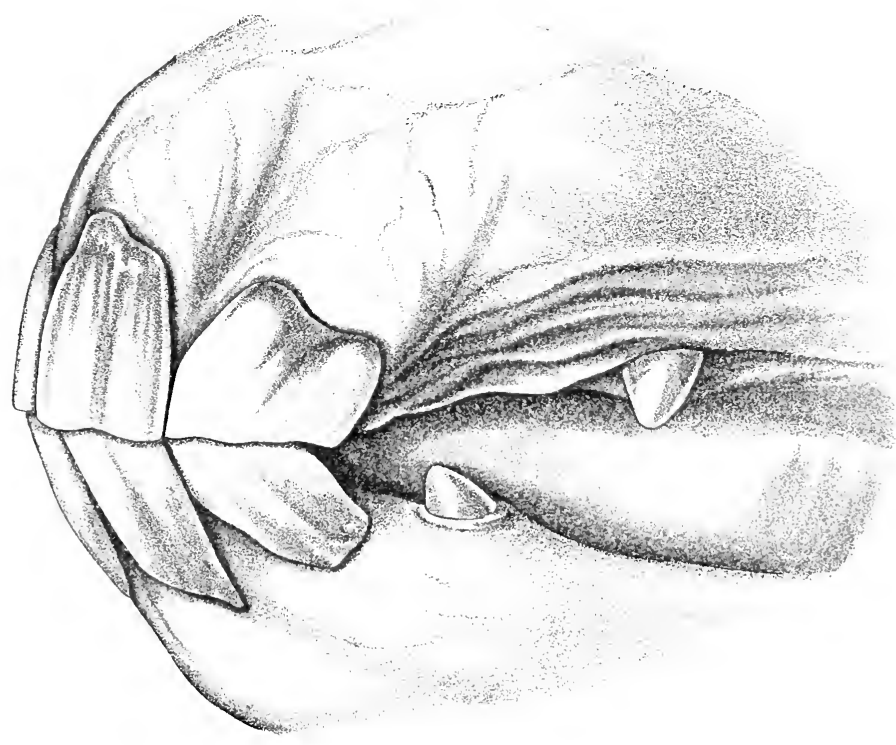

\section{YeArs OfF.}




\section{FIVE YEARS OFF.}

The corner incisors show slight wear, and their posterior edges are round.

\section{SIX YEARS OFF.}

The corner incisors begin to show uneven edges, and the posterior margin of both upper and lower corner teeth not so rounded. 


\section{SEVEN YEARS OFF.}

The corner incisors now begin to show considerable wear. The tush at this age still remains fairly sharp.

\section{EIGHT YEARS OFF.}

Considerable wear of the corner incisor seen. The gum of corner incisor of the lower jaw has become straight. 


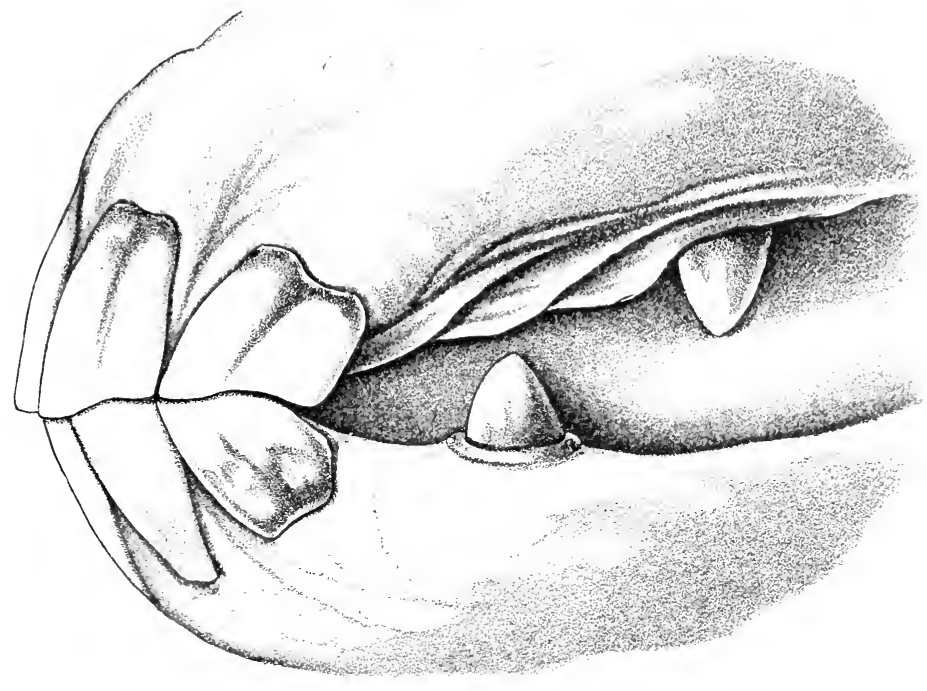

\section{Years 0fF.}

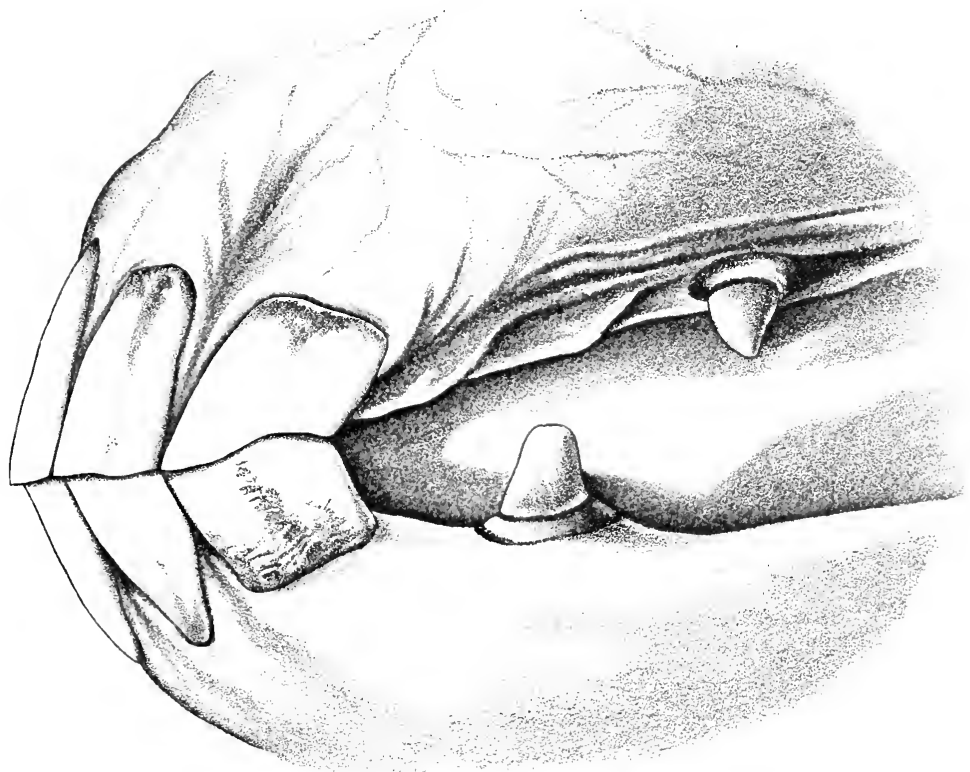

8 YeARs 0FF. 

$\therefore$ 
filling up, and in some cases have disappeared. In most mouths at this age the posterior margin of the upper corner incisor projects in a downward direction, and when this projection is present, the examiner may be certain that the animal he is looking at is seven years off, for it is seldom, if ever, seen previously to the horse having passed its seventh year. The infundibulum of the corner incisor is now surrounded by a flat surface.

Eight Years Off.-At this age the gum of the bottom corner incisor has become quite square, and the tush of the lower jaw blunted. The table of the corner incisor is quite conpleted and the infundibula nearly entirely obliterated. The tables of the central incisors are getting angular in shape, and those of the lateral incisors are following suit. The infundibula are frequently obliterated; but, as a rule, those of the lateral and corner incisors are still present in a more or less marked degree.

After the eighth year, at which period of its life the horse is termed aged, there is no certainty 
86 EXAMINATION OF HORSES AS TO SOUNDNESS

of being able to tell its correct age by the teeth, although very often a fairly correct opinion can be formed; but for all practical purposes the limit of eight years is sufficient.

THE END. 


\section{ALPHABETICAL INDEX OF WORKS,}

IN

MEDICINE, SURGERY, SCIENCE AND ART,

PUBLISHED BY

\section{BAILLIËRE, TINDALL, \& COX.}

Abdominal Surgery. Colotomy, Inguinal, Lumbar or Transverse, for Cancer, or Stricture with Ulceration, of the large Intestine. By Herbert W. Allingham, F.R.C.S., Surgeon to the Great Northern Hospital, Assistant Surgeon to St. Mark's Hospital for Diseases of the Rectum, Surgical Registrar to St. George's Hospital. With 32 illustrations. Price 6s.

Abdominal Surgery. The Surgical Diseases and Injuries of the Stomach and Intestines. By F. Buwreman Jessett, F.R.C.S. Eng., Surgeon to the Cancer Hospital. Illustrated. Price 7s.6d.

Abortion. Causes and Treatment of Abortion. By R. REID Rentoul, M.D. Price 10s. 6d.

Africa. A Contribution to the Medical History of our West African Campaigns. By Surgeon-Major AlBert A. Gore, M.D., Sanitary Officer on the Staff. Price 10s. 6d.

Alcoholism. Alcoholism and its Treatment. By Johx E. Usher, M.D., F.R.G.S. Price 3s. 6d.

"Will be found interesting and suggestive."-The Times.

"A very full account of the methods of treating the disease of inebriety is contained in this interesting work."-British Medical Journal.

Ambulance. Questions and Answers on "First Aid to the Injured." By John W. Martin, M.D., and John Martin, F.R.C.S. Forty-second thousand. Price 1s. net.

Anæsthetios. History of Surgical Anæsthesia. By H. Bellany Gardner. Price ls.

Anæsthetics. Selected Methods in the Administration of Nitrous Oxide and Ether. By Frederic Hewitt, M.A., M.D. Cantab., Lecturer on Anæsthetics at the London Hospital. Price 2s. 6d.

Anæsthetics: Ancient and Modern. Their Physiological Action, Therapeutic Use, and Mode of Action. By GEorge Foy, F.R.C.S., Surgeon to the Richmond Hospital. Price 3s. 6d. net.

Anatomography; or, Graphic Anatomy. A new method of grasping and committing to memory the most difficult points required of the student. By W. Darling, M.D., F.R.C.S. Eng., Professor of Anatomy in the University of New York. Price 1s. 
Anatomy. Human Anatomy and Physiology. Illustrated by a series of Movable Atlases of the Human Body, showing the relative positions of the several parts, by means of Superposed Coloured Plates, from the designs of Professor G. J. WiTkowskI, M.D. Each part complete in itself. Price 7s. 6d. net.

Part I.-Neck and Trunk. With Text Descriptive and Explanatory of the physiology and functions of the several parts. By Robert Hunter Semple, M.D., F.R.C.P. Lond. Price 7s. 6d.

The same enlarged to Life Size. Price 25s. net.

Part II.-Throat and Tongue, showing the Mechanism of Voice, Speech, and Taste. Text by Lennox Browne, F.R.C.S. Ed. Price 7s. 6d.

Part III.-The Female Organs of Generation and Reproduction. Text by James Palfrey, M.D., M.R.C.P. Lond., late Senior Obstetric Physician, London Hospital. Price 7s. 6d.

Part IV.-The Eye and the Apparatus of Vision. Text by Henry Power, F.R.C.S., Senior Ophthalmic Surgeon to St. Bartholomew's Hospital. Price 7s. 6d.

Part V.-The Ear and Teeth. The Mechanism of Hearing and of Mastication. Text of the Ear by Lennox Browne, F.R.C.S. The Teeth by H. SewILl, M.R.C.S. Price 7s. 6d.

Part VI.-The Brain and Skull. (Cerebrum, Cerebellum, and Medulla Oblongata.) Text by T. Stretch Dowse, M.D., F.R.C.P. Ed. Price 7s. 6d.

Part VII.-The Nale Organs of Generation. Text by D. Canpbell Black, M.D., Physician to the Glasgow Royal Infirmary. Price 7s. 6d.

Part VIII.-The Skeleton and its Articulations, showing the Bones and Ligaments of the Human Body and Limbs. Text by A. T. Norton, F.R.C.S. Price 7s. 6 d.

Part IX.-The Hand; its Bones, Muscles and Attachments. Text by Jas. Cantuie, M.B., F.R.C.S. Price 7s. 6 d.

Part X.-The Foot; its Bones, Muscles and Attachments. Text by Stanley Boyd, M.B., B.S. Lond., F.R.C.S., Assistant Surgeon, Charing Cross Hospital. Price 7s. 6d.

Part XI.-Progress of Gestation. A Synopsis of Practical Obstetrics. Text by R. Milne Murray, F.R.C.P. Edin., M.B. Edin. Price $7 \mathrm{~s} .6 \mathrm{~d}$.

The Set of Eleven Parts, complete in cloth-covered Box, with lock and key, £4 net.

** No such simple, reliable, and comprehensive method of learning the several parts, positions, and functions of the body has hitherto been attempted ; the entire Series is unique, and will be most valuable to the Teacher, the Student, and to all who wish to become acquainted with the anatomy and physiology of the human economy. 
Anatomy. Aids to Anatomy. By George Brown, M.R.C.S., and P. Macleod Yearsley, F.R.C.S. Price 2s. 6d. cloth, 2s. sewn.

Anatomy. A Handbook of Pathological Anatomy and Histology. By Francis Delafield, M.D., LL.D., and T. Mitchell PRUdDEx, M.D. Illustrated by 365 wood engravings in black and colours. Fifth edition. Price 25s.

Anatomy. Atlas of Pathological Anatomy. By Prof. C. Bollinger. Illustrated with 120 coloured Plates.

[In preparation.

Anatomy. Text-Book of Naked-Eye Anatomy. With 113 Steel Plates, designed under the direction of Professor Masse. Text by Jas. CAntLie, M.B., C.M. (Honours), F.R.C.S., Charing Cross Hospital. Third edition. Plain, 25s., coloured, 50s., half calf.

Anatomy. The Essentials of Anatomy. A Text-book for Students and a book of easy reference to the Practitioner. By W. Darling, M.D., F.R.C.S., and A. L. Ranney, M.D. 12s. 6d.

Anatomy. Aids to Surgical Anatomy. By Eugene S. Yonge, M.B. Price 2s. 6d. cloth; 2s. paper.

Anatomy. The Pocket Gray, or Anatomist's Vade-Mecum. Com. piled from the works of Gray, Ellis, Holden, and Leonard. By E. CotTerelL, F.R.C.S. Eng., late Demonstrator of Anatomy, University College, London. Fourth edition, 3s. 6d.

"A marvellous amount of information condensed into a remarkably small space."-Med. Press.

Anatomy, Schematic Anatomy; or Diagrams, Tables and Notes treating of the Association and Systematic arrangement of Structural Details of Human Anatomy. By William P. Mears, M.B., Professor and Examiner in Anatomy at the University of Durham. Profusely illustrated. Price 7s. 6d.

Anatomy. Aids to Comparative Anatomy and Zoology. By Major Greenwood, MI.D., Honours. Price 2s. 6d. and 2s.

Apoplexy. On Stertor, Apoplexy, and the Management of the Apoplectic State. By RoBERT L. Bowles, M.D., F.R.C.P. Lond., Consulting Physician to the Victoria Hospital, and to the St. Andrew's Convalescent Hospital, Folkestone. With 13 illustrations. Price 4s. 6d.

"Based on extensive clinical and experimental investigation. The principles deserve to be more widely known and acted on."-British Medical Joumal.

"A book which is at present the only authority on the subject."-Medicai Press.

Army Hygiene. Lessons in Military Hygiene and Surgery. By Surgeon-General Sir C. A. GoRdor, M.D., K.C.B., Hon. Physician to H.M. the Queen. Illustrated. Price 10s. 6d.

Artistic Anatomy. Anatomy of the External Forms of Man, for the use of Artists, Sculptors, etc. By Dr. J. FAU. Used at the School of Art, South Kensington. Twenty-nine plates. Folio. New edition. 30s, coloured, 15s. plain. 
Artistic Anatomy. Elementary Anatomical Studies of the Bones and Muscles, for Students and Schools, from the drawings of J. Flaxman, R.A. Used in the Art Schools at South Kensington. 20 plates, with Text, price 2s.

Artistic Anatomy. The Student's Manual of Artistic Anatomy. With 25 etched plates of the bones and surface muscles of the human figure. By W. J. Muckley. Used at the Art Schools, South Kensington. Second edition. Price 5s. 6d.

Artistic Anatomy. Elementary Artistic Anatomy of the Human Body. From the French of Dr. FAU. With English Text. Used at the School of Art, South Kensington. Price 5s.

Artistic Anatomy. A Manual of Artistic Anatomy for the use of Students in Art. Description of the Bones and Muscles that influence the External Form of Man. With 43 plates. By John C. L. Sparkes, Principal of the National Art Training School, South Kensington. Price 7s. 6d.

Artistic Drawing. Elementary (Second Grade) Perspective (Theory and Practice), containing 30 block illustrations, 21 plates, and many examination exercises. Used at the Science and Art Schools. By H. J. Denvis, Art Master, Lambeth School of Art, Dulwich College, etc. Price 2s. 6d.

Artistic Drawing. Advanced (Third Grade) Perspective, for the use of Art Students. By H. J. Dennis. Used at the Science and Art Schools. In two parts, 7s. 6d. each. Part 1, Angular and Oblique Perspective. Part 2, Shadows and Reflections. Or complete in one vol., half-bound leather, price $15 \mathrm{~s}$.

Artistic Drawing. Second Grade Perspective Test Papers. By H. J. Dennis. Price $1 \mathrm{~s}$.

Artistic Drawing. Elementary Freehand, Drawing Copies. Approved by the Science and Art Department. Price 1s.

"An introduction and skeleton figures make the book a real boon to the teacher." Correspondent.

Artistic Drawing. Advanced Freehand Ornament, Second Grade. Price 2s.

Artistic Drawing. The Prototype of Man, giving the natural laws of Human proportion in both sexes. A manual for artists and professors of drawing. By Chas. Rochet, of Paris. Price 1s.

Artistic Drawing. A Manual of the Proportions of the Human Body for Artists. By Bertram C. A. Windle, M.A., M.D., D.Sc., Queen's Professor of Anatomy in the Mason College, Professor of Anatomy to the Royal College of Artists, and Lecturer in the Municipal School of Birmingham. Price 2s. 
Artists' Colours. Their Preparation, Uses, etc. See Colours.

Asthma. On Asthma and Chronic Bronchitis - their Causes, Pathology and Treatment. Lettsomian Lectures. By J. C. THORowGO0D, M.D., F.R.C.P. London, Senior Physician to the City of London Hospital for Diseases of the Chest. Fourth edition. Price $4 \mathrm{~s}$.

"Plenty of useful information will be derived from the reading of the book."-Provincial Medical Journal.

Asthma. See also Bronchitis.

Astronomy. The Stars and the Earth; or, Thoughts on Time, Space, and Eternity. With Notes by R. A. Proctor, B.A. Fourteenth thousand. Price 1s.

Ataxia. Nervous Affections associated with the Initial or Curative Stage of Locomotor Ataxy. By T. Stretch Dowse, M.D., F.R.C.P.E. Second edition. Price 2s.

Bacteriology. Applied Bacteriology. By T. H. Pearmain and C. G. Murr, M.A. A Handbook for the Use of Students, Medical Officers of Health, Analysts, etc. Price 12s. 6d. net.

"A timely and useful contribution to our hygienic literature."-Chemical News.

Bacteriology. Atlas and Essentials of Bacteriology. By Prof. K. B. Lehinann and Dr. R. Neumann, of Würzburg. Illustrated with 63 coloured plates, comprising 558 figures and numerous woodcuts. Price 12s. 6d.

Vol. V.-Hand-Atlas Series.

Bacteriology. Bacteria of the Sputa and Cryptogamic Flora of the Mouth. By Filandro Vicentini, M.D. Translated from the Italian by the Rev. E. J. StutLer and Prof. E. Saieghi. Price 7 s. 6d.

Bacteriology. Bread, Bakehouses and Bacteria. By F. J. WALDO, M.D. Cantab., and David Walsh, M.B., C.M. Edin. Price 2s. "Of universal interest."-St. Poul's.

Bacteriology. Guide to the Demonstration of Bacteria in the Tissues. By Dr. H. KüHNE, of Wiesbaden. Translated by VincenT Dornier Harris, M.D. Lond., F.R.C.P. Price 2s. b́d.

Bacteriology. Microbes in Fermentation, Putrefaction, and Disease. By Charles Cameron, M.D., LL.D., M.P. Price 1s. Professor Tyudall, F.R.S., writes: "Matthew Arnold himself could not find fault with its lucidity, while as regards knowledge and grasp of the subject $I$ have rarely met its equal."

Bacteriology. Researches in Micro-Organisms, including recent Experimentsin the Destruction of Microbes in Infectious Diseases, etc. By A. B. Grifriths, Ph.D., F.C.S., F.R.S.E. With 52 illustrations. Price 6s. 
Bacteriology. Bacteriological Diagnosis. By St. George Reid, Bacteriologist to the Central London Throat and Ear Hospital. Price 2s. 6d.

Bacteriology. Aids to Bacteriology. By H. T. Pearmain and C. G. Mloor, M.A., F.C.S., Members of the Society of Public Analysts. Price 3s. 6d. cloth; 3s. paper wrapper.

Bandaging. Bandaging: a Manual for Self-instruction. By C. H. LEONARD, A.M., M.D., Professor in the State College, Michigan. With 139 illustrations. Price 3s. 6d.

Biology. Aids to Biology. Prepared to meet the requirements of students reading for the first examination of the Conjoint Board. By Joseph IV. Willians. Price 2s. paper; 2s. 6d. cloth.

Bladder. On Diseases of the Bladder, Prostate Gland, and Urethra. By F. J. Gant, F.R.C.S., Senior Surgeon to the Royal Free Hospital. Fifth edition. Price 12s. 6d.

Blindness. See Eye.

Botany. A Dictionary of British Plants and Flowers ; their names, pronunciation, origin, etc. For the use of Amateurs and Beginners. By H. P. Fitzgerald. Price 2s. 6d.

Botany. Aids to Botany. Outlines of the Elementary Facts, including a Description of some of the most impurtant Natural Orders. By C. E. Armand Semple, B.A., M.B. Cantab., M.R.C.P. Lond. Price 2s. 6d. cloth; 2s. paper wrapper.

Brain. Brain Surgery. By W. Allen Stare, M.D., Ph.D. Professor of Mental Diseases in the College of Physicians and Surgeons, New York. With 59 illustrations. Price 10s. 6d.

Brain. Dreamy Mental States. The Cavendish Lecture. By Sir J. Crichton Browne, M.D., F.R.S. Price 1s.

"Sir James declares that means will ke found, under the guidance of modern study of brain functions, to strengthen defective portions of the organs, and to bring all the mental faculties successively into hygienie activity."-Times.

" 'Ureamy Mental States,' as morbid states, ought to be studied, and their subjects subjected to treatment, especially of children and soung people."-Cleristien World.

Brain. The Building of a Brain. By E. H. Clarke, M.D. (author of "Sex in Education"). Price 5s.

"Carefully and e'egantly written, and full of sound physiology."-Lancet.

Brain. On Irritable Brain in Children. By W. H. DAY, M.D., M.R.C.P. Lond., Physician to the Samaritan Hospital for Women and Children. Price 1s. 6d.

Brain. The Physiological and Chemical Constitution of the Brain, based on original researches. By J. L. W. Thudichum, M.D., F.R.C.P. Lond. Price 10s. 6d. 
Brain. Syphilis of the Brain and Spinal Cord, in the production of Paralysis, Epilepsy, Insanity, and other Mental and Nervous Derangements. By T. StreTch Dowse, M.D., F.R.C.P. Ed. Second edition, illustrated. Price 5s.

Brain. On Brain and Nerve Exhaustion (Neurasthenia), and on the Exhaustions of Influenza. By the same Author. Price 2s. 6d.

Brain. Microscopical Examination of the Human Brain, Methods of Research, etc. By Edwin Goodall, M.D. Lond. Price 5s.

Bread. Bread, Bakehouses, and Bacteria. By F. J. Waldo, M.A., I.D. Cantab., and D. Walsh, M.D., C.M. Edin. Price 2s. cloth ; 1s. paper.

Bread. Does Baking Sterilize Bread? By F. J. WALdo and D. IVALSH. Price 6d.

Breath. The Breath and Diseases which give it a Foetid Odour. By J. W. Howe, M.D. Third edition. Price 2s. 6d. net.

Bronchi. The Bronchi and Pulmonary Bloodvessels. Their Anatomy and Nomenclature, with a Criticism of Professor Aeby's Views on the Bronchial Tree of Mammalia and Man. By W. Ewart, M.D. Cantab., F.R.C.P. Lond., Physician to St. George's Hospital. Price 21s.

Bronchitis. Chronic Bronchitis : its Forms and Treatment. By J. Milner Fothergill, M.D. Ed., M.R.C.P. Lond. Price 4s. 6d.

Burmah. Our Trip to Burmah, with Notes on the Ethnology, Geography, Botany, Habits and Customs of that Country. By Surgeon-General Gordon, C.B., M.D., Physician to the Queen. Illustrated with numerous Photographs, Maps, Coloured Plates, and Sketches in gold by native Artists. Price 21s.

Cancer. The Objects and Limits of Operations for Cancer, with special reference to Cancer of the Breast, Mouth and Throat, and Intestinal Tract. Being the Lettsomian Lectures for 1896. By W. Watson Cheyne, M.B., F.R.S., F.R.C.S., Professor of Surgery at King's College. Price 5s.

"These lectures will do much to encourage surgeons in dealing with cancer of the breast, mouth, and throat."-Glasgow Medical Journal.

"Mr. Cheyne's lectures should be carefully examined by every practical surgeon."Medical Piess.

Cancer. Cancer and its Complications. Its Local Origin, Preventive and Curative Treatment. By C. E. Jennisgs, F.R.C.S. Eng., M.S., M.B. Second edition. Price 3s. 6d. net.

Cancer. Cancer of the Mouth, Tongue and Esophagus. By F. Bowreman JessetT, F.R.C.S. Eng., Surgeon to the Cancer Hospital. Price 6s.

Cancer. Lectures on Cancer of the Uterus, with Cases. By F. Bowreman Jessett. Price 3s. 6d. 
Cancer. Cancer, Sarcoma, and other Morbid Growths considered in relation to the Sporozoa. By J. Jackson Clarke, M.B. Lond., F.R.C.S., Curator of the Museum, and Pathologist at St. Mary's Hospital. Illustrated. Price 3s. 6d. net.

"For those who wish to obtain a general outline of the subject treated, the abstracts and references given by the author will render this a comparatively easy task." - Nature.

Case Book. A Pocket Case-book for Practitioners and Students. With diagrams, charts, and suggestions for note-taking. By Alex. Theodore Brand, M.D., C.M. Bound in limp leather cover. Price 4s. Loose sheets per doz. 1s., 50 3s. 6d., 100 6s.

Case Book. Student's Case-book. For recording cases as seen, with full instructions for methodising clinical study. By GEOrGE Brown, M.R.C.S., Gold Medallist, Charing Cross Hospital. Fourth thousand, cloth. Price 1s. net.

Case Taking. Cardiac Outlines for Clinical Clerks and Practitioners; and First Principles in the Physical Examination of the Heart. By W. Ewart, M.D., F.R.C.P. Lond., Physician to St. George's Hospital, London. With fifty illustrations. Price 5s. 6d.

* * A supply of thoracic and cardiac outlines ( $4 \frac{1}{2}$ by $3 \frac{3}{4}$ inches), on gummed paper, is included in each copy. Separately $9 \mathrm{~d}$.

Case Taking. Symptoms and Physical Signs, a formulary for medical note-taking. By the same Author.

[Neu: edition in preparation.

Catarrhs. Home Treatment for Catarrhs and Colds. By LEONARD A. Dessar, M.D. Illustrated. Price 5s.

Chemistry. Aids to Chemistry. By C. E. Armand Seniple, B.A., M.B. Cantab., M.R.C.P. Lond.

Part I.-Inorganic. The Non-metallic Elements. Price, cloth 2s. 6d.; paper 2s.

Part II.-Inorganic. The Metals. Price 2s. 6d. cloth; 2s. paper. Part III.-Organic. Price, cloth, 2s. 6d.; paper, $2 \mathrm{~s}$.

Part IV.- Tablets of Chemical Analysis. Price 1s. 6d. and 1s.

Chemistry. A Short Manual of Analytical Chemistry for Laboratory. Use. By John Muter, Ph.D., M.A., F.C.S. Sixth edition revised. Price $6 \mathrm{~s}$. 6 d.

Chemistry. Chemical Notes and Equations. Inorganic and Organic. By G. H. Gemiell, F.I.C., F.C.S. Lecturer on Chemistry, Edinburgh. Price 5s.; interleaved, $7 \mathrm{~s} .6 \mathrm{~d}$.

"Gives in condensed form many jmportant faets and equations specially useful to students." - Elinburgh Medical Jourial.

"For refreshing the memory of the student, the book would serre admirabls."-British and Colonial Druggist.

"This is just what the first-year students want."-Student.

Chemistry. Dictionary of the Active Principles of Plants: Alkaloids, Bitter Principles, Glucosides, with tabular summary and classification of Reactions. By Charles E. SoHn, F.I.C., F.C.S. Price 10s. 6d. 
Chemistry. Guide to the Conjoint Board Examinations. By P. A. E. Richards, F.I.C., F.C.S. Price 2s. 6d.

"A useful guide in elementary practical ehemistry."-Phamaceutical Journal.

"It gives all the information generally required by medical students on the subjeet." British and Colonial Diuggist.

Chemistry. Manual of Chemistry. A Guide to Lectures and Laboratory Work for Beginners in Chenistry. By W. Simon, Ph.D., M.D. With 16 illustrations and 7 coloured plates. Price $15 \mathrm{~s}$.

Chemistry. The Principles of Theoretical Chemistry, with special reference to the Constitution of Chemical Compounds. By IRA Remsen, M.D., Ph.D., Professor of Chemistry in the Johns Hopkins University. 5th edit., enlarged and revised. 7s. $6 \mathrm{~d}$.

Chemistry. The Progress of Medical Chemistry, its Application to Physiology, Pathology, and the Practice of Medicine. By J. L. W. Thudichun, M.D., F.R.C.P. Lond., M.R.C.S. Eng., Carola-Ruperta Gold Medallist. Price 5s.

Chemistry. The Student's Chemistry. Part I. The Nonmetallic Elements. By A. C. Maybury. Price $4 \mathrm{~s}$.

Chemistry. The Student's Hand-book, with Tables and Chemical Calculations. By H. Leicester Greville, F.I.C., F.C.S. Second edition. Price 6 s.

Children. Aids to the Diagnosis and Treatment of Diseases of Children. By John MCCAw, M.D., L.R.C.P. Price 3s. 6d., cloth ; 3s. paper cover.

Children. Confidential Chats with Mothers on the healthy rearing of Children. By Mrs. Bowdich. Price 2s.

Children. Practical Guide for the Young Mother. By Dr. Brochard. Price 2s.

Children. The Nervous Diseases of Children. An original work treated in an original manner. By B. SACHS, M.D. Professor of Mental and Nervous Diseases in the New York Polyclinic. With 170 plain and coloured illustrations. Price 21s.

"Carefully compiled and well illustrated."-British Medical Journal.

"A most admirable treatise on a very important and too much neglected subjeet."Boston Medical and Surgical Journal.

Children. The Diseases of Children : their History, Causes and Treatment. By C. E. Armand Semple, B.A., M.B. Cantab., M.R.C.P. Lond. Price 6s.

Children. How to Feed an Infant. With an Appendix on the Common Ailments of Infancy, with their Hygienic and Curative Treatment. By Benson Baker, M.D. Price 1s. 6d. 
Children. How to bring up Children by Hand. By J. Foster PALMER, L.R.C.P. Price 6d.

Chlorosis. Chlorosis, the Special Anæmia of Young Women. Its Causes, Pathology, and Treatment. By E. Lloyd Jones, M.D., B.C. Cantab., Pathologist for the staff of Addenbrooke's Hospital, Cambridge. Price 2s. 6d.

Cholera: How to Prevent and Resist it. By Professor von PettenKofer and T. Whiteside Hine, A.B., M.B. Second edition. Illustrated. Price 3s. 6d.

Cholera. The Cholera Microbe and How to Meet It. Read at the Congress of the British Medical Association. By Charles Cameron, M.D., LL.D., M.P. Price 1s.

Climatology. Health Resorts of Australia. By L. Bruck. Price 2s. 6d.

Climatology. The Book of Climates in all Lands. A Handbook for Travellers, Invalids, and others in search of Health and Recreation. By D. H. Cullimore, M.D., M.R.C.P. Lond. With a chapter on the Climate of Africa by Surgeon PARKE, D.C.L. Second edition. Price 4s. 6d.

Climatology. The Island of Madeira. A Resort for the Invalid and a Field for the Naturalist. By Surgeon-General Sir C. A. Gordon, M.D., K.C.B., Hon. Physician to the Queen. 2s. 6d.

Climatology. Ventnor and the Undercliff. By.J. M. Williamson, M.D., MI.B. Ed., Hon. Surgeon to the National Hospital for Consumption. Second edition. Price 1s.

Coca. The Coca of Peru, its Remedial Principles, and Healing Powers. By J. L. W. Thudichun, M.D., F.R.C.P. Price 1s.

Colours. A Handbook for Painters and Art Students, on the character, nature, and use of Colours. By W. J. MUCkLey. Fourth edition enlarged. Price 4s.

Consumption. Consumption as a Contagious Disease ; the Merits of the Air of Mountains and Plains. By D. H. Cullimore, M.D., M.R.C.P. Lond., formerly H.M. Indian Army. Price 5s.

Consumption. Consumption and its Treatment by the Hypophosphites. By JoHN C. THorowgood, M.D., F.R.C.P. Lond., Physician to the City of London Hospital for Diseases of the Chest, Victoria Park. Third edition. Price 2s. $6 \mathrm{~d}$.

Consumption. Lectures on the Prevention of Consumption. By Willian Murrell, M.D., F.R.C.P. Lond., Physician to Outpatients at the Westminster Hospital. Price 3s. 6d.

"The book is well worth a careful study."-Leeds Mereury.

"The lectures are eminently practical and lucid."-Gilasgoo Herald.

"We can warmly recommend this little book."-Daily Chronicle. 
Consumption. The Animal Tuberculoses and their relation to Human Tuberculosis. By E. Nocard, translated by H. ScurFIELD, M.D. Edin., D.P.H. Camb. Price $4 \mathrm{~s}$.

"An enormous amount of interesting and valuable information."-Dublin Medical Journal. "A welcome addition to the books of its kind."-Bombay Eust lindicn.

Consumption. The Pathology of Tuberculosis (Pulmonary Tuberculosis and Tubercular Phthisis). Post Graduate Lectures delivered at Queen's Hospital, Birmingham. By Geo. F. Crooke, M.D., Physician and Pathologist to Queen's Hospital, and Lecturer on Pathology in Queen's College. Price 2s. 6d.

Consumption. Tuberculosis from a Sanitary and Pathological Point of View. By G. Fleming, C.B., F.R.C.V.S., President of the Royal College of Veterinary Surgeons. Price 1s.

Deaf-mutism. On the Education of Deaf-mutes by Lip-Reading and Articulation. By Professor Hartuann. Translated by Dr. Patterson Cassells. Price 7s. 6d.

Deafness. Vascular Deafness. By R. T. Cooper, M.A., M.D. Price 3s. 6d.

Death. Death and Sudden Death. By P. Brouardel, Senior Physician of the Faculty of Medicine of Paris. Translated by F. L. Benhan, M.R.C.P. Price 10s. 6d.

Deformities. A Practical Treatise on Orthopædic Surgery. For the use of Practitioners and Students. By James K. Young, M.D., Instructor in Orthopædic Surgery, University of Pennsylvania. Price 18 s.

Deformities. Deformities of the Human Foot, by W. J. Walshain, II.B., F.R.C.S., Senior Assistant Surgeon to St. Bartholomew's Hospital, and W. Kext Hughes, M.B. Lond., M.R.C.S.E. Price $18 \mathrm{~s}$.

Deformities. The Surgical Treatment of Deformities. By War. ADAls, F.R.C.S. Price 2s. 6d.

Deformities. Three Lectures on the Growth Rates of the Body and the Limbs, in Relation to the Processes of Rectification of Deformity. By Walter Pye, F.R.C.S. Eng. Price ls.

Dental. Aids to Dental Surgery. By Arthur S. Underwood, M.R.C.S., L.D.S. Eng. Price 2s. 6d. cloth; 2s. paper.

Dental. Aids to Dental Histology. By the same author. Price 2s. 6d. cloth; 2s. paper.

Dental. Manual for the Dental Laboratory. A Practical Guide to its Management, Economy, and Methods of Manipulation. By Charles Hunter. Price 3s. 6d.

Dental. Extraction. See Teeth.

Dental. Guide to the Medical and Dental Profession. By Percival Turner. Price 3s. 6d. 
Dental. A Manual of Dental Surgery: Including Special Anatomy and Pathology. For Students and Practitioners. By HeNRY SEwILL, M.R.C.S., L.D.S. Eng. Third edition, with upwards of 200 illustrations. Price 10s. 6d.

Dermoids. Dermoids, or Tumours containing skin, hair, teeth, etc. By J. Bland Sutton, F.R.C.S. Illustrated. Price 3 s.

Diabetes. Diabetes and its Treatment. By A. Vintras, M.D., Senior Physician to the French Hospital, London. 1s. 6d.

Diagnosis. The Diagnosis of Disease. By J. Porter Parkinson, M.D., M.R.C.P. Lond., F.R.C.S. Eng., Medical Registrar to the Westminster Hospital, and Assistant Physician to the Hackney Childrens' Hospital, etc., etc. 21 illustrations. Price 4s.

Diagnosis, Aids to Diagnosis. Three Parts. 1s. and 1s. 6d. each. Part I. -Semeiological. By J. Milner Fothergill, M.D.

Part II._Physical. By J. C. ThoRowgood, M.D., F.R.C.P. Part III.-What to Ask the Patient. By J. Milner Fothergill, M.D.

Or in 1 vol. Edited by Dr. Thorowgood. Price 3s. 6d. cloth.

Diagnosis. The Physiological Factor in Diagnosis. By J. Milner Fothergill, M.D., M.R.C.P. Lond. Second Ed. Price 7s. 6d.

Dictionary. Illustrated Dictionary of Medicine, Biology, and Allied Sciences, including Pronunciation, Derivation, etc. $\mathrm{By}$ George M. Gould, A.M., M.D. Half morocco. Price 40s, net.

Dictionary. English-French and French-English Dictionary of Medical Terms. In two parts. By H. DE MÉric, MI.R.C.S. Eng., Surgeon French Hospital and Dispensary. [In the Press.

Dictionary. A Vest-Pocket Medical Dictionary, including Pronunciation. By Albert H. Buck, M.D. 529 pages. Price 3s. net.

Dictionary. Dictionary of British Plants and Flowers. Their Names, Pronunciation, Origin, etc. For the use of amateurs and beginners. By H. P. FitzGerald. Price 2s. 6d.

Dictionary. Dictionary of German Medical Terms. By G. R. CutTer, M.D. Price 6s. 6d.

Dictionary. Dictionary of Active Principles of Plants : Alkaloids, Bitter Principles, Glucosides, with tabular summary and classification of Reactions. By C. E. SoHs, F.I.C., F.C.S. 10s. 6d.

Dictionary. Dictionary of Materia Medica and Therapentics. A Synopsis of all Drugs in Common Use. By C. Hesri Leonard, A.M., M.D., and Thomas Christy, F.L.S., F.C.S. Price 6s.; half morocco, 8 s. $6 \mathrm{~d}$. 


\section{0 and 2 I, King William Street, Strand. I 3}

Diphtheria. A Practical Treatise on Diphtheria and its successful Treatment. By B. R. MARTin, M.B. Dub. Second edition. Price 2s.

Diphtheria. Diphtheria and its Associates. By Lennox Browne, F.R.C.S. Edin. Second Edition. Price 16s.

"Passes in review the recorded experience of many observers. Is copiously illustrated from his own admirable drawings, which, as well as the reproduction of them, are worthy of all praise."-Times.

"Contains much information for nurses and others in attendance upon diphtheritic patients."-Moining Post.

"Reflects the best spirit of safe and sane medical treatment, based on long experience and patient inquiry."-Daily Telegraph.

Disease. A Study. By J. Milner Fothergill, M.D. Edin., M.R.C.P. Lond. Price 1s.

Diseases. The Classification and Nomenclature of Diseases. By A. Rabagliati, M.A., M.D., Senior Surgeon Bradford Infirmary, Surgeon to the Children's Hospital. Price 2s. 6d.

Ear. Diseases of the Ear. By George P. Field, M.R.C.S., Aural Surgeon to St. Mary's Hospital, and Lecturer on Aural Surgery. Fifth edition, enlarged, with 23 coloured plates and numerous woodcuts. Price 12s. 6d.

Ear. Text-book of Diseases of the Ear and Adjacent Organs. By Professor Politzer, of Vienna. Translated from the third German edition by OSCAR DodD, M.D., and Edited by SIR Wu. Dalby, B.A., M.B., F.R.C.S. Profusely illustrated. Price 21s. "Contains all that is known upon the subject."-Lancet.

Ear. The Anatomical and Histological Dissection of the Human Ear, in its Normal and Diseased Conditions. By Professor Politzer, of Vienna. Translated at the author's request by George Stone, F.R.C.P. Ed. Profusely illustrated. 10s. 6d.

Ear. Aids to Otology. By W. R. H. Stewart, F.R.C.S. Ed. Price 2s. 6d. cloth ; 2s. paper.

Ear. Subjective Noises in the Head and Ears. Their Etiology, Diagnosis and Treatment. By H. Macnaughton Jones, M.D., F.R.C.S. I. and Ed. Profusely illustrated, price 4s. 6 d.

Ear. The Hygiene of the Ear. By Cavaliere Vincenzo CozzoLINo, Professor in the Royal University of Naples, and Director of the Hospital Clinic for Diseases of the Ear, Nose, and Throat. Translated from the fifth Italian edition by JaMes ERSkine, M.A., M.B. Price 1s.

Ear. Practitioner's Hand Book of Diseases of the Ear and NasoPharynx. By H. Macnaughton Jones, M.D., F.R.C.S. I. and Ed., and W. R. H. Stewart, F.R.C.S. Ed. Fifth edition, with plates and numerous woodcuts. Price 10s. $6 \mathrm{~d}$. 
Electricity. A Manual of Practical Medical Electricity. With Chapters on the Röntgen Rays. By Dawson Turner, B.A., M.D., F.R.C.P. Ed., M.R.C.P. Lond. Second edition. Price $7 \mathrm{~s} .6 \mathrm{~d}$.

"Valuable alike to students and practitioners."-Practitioner.

"A thoroughly reliable and practical manual of the subject."-Medical Press and Circular.

Electricity. The Röntgen Rays in Medical Work. By Darid WaLsh, M.D., Physician to Western Skin Hospital, Hon. Sec. Röntgen Society, London. With an Introductory Section upon Electrical Apparatus and Methods by J. E. Greenhill. Illustrated with 59 plates and woodcuts. Price 6 s. net.

Electricity. Electricity in General Practice. By W. BuLtoN Tomson, M.D. Price 2s. 6d.

Etiquette. A few Rules of Medical Etiquette. By a L.R.C.P. Lond. Price $1 \mathrm{~s}$.

Examination Cards: Questions and Answers. By A. T. ScHoFIELD, M.D. Pathology, 2 sets, 9d. each, net. Minor Surgery, Bandaging, etc., 9d., net.

Examinations. A Guide to the Examinations of the Conjoint Board in England and for the Fellowship of the College of Surgeons, with Examination Papers. By F. J. Gant, F.R.C.S. Sixth edition, revised and enlarged. Price 5s. net.

[New edition in preparation.

Examinations. A Guide to the Examinations of the Apothecaries Society of London, with Questions, Tables on Materia Medica, etc. By W. E. Dawson, L.S.A. Second edition. Price 2s. 6 d.

Examinations. Aids to Examinations. By D. WALSH, M.D., C.M, L.R.C.P. Being Questions and Answers on Materia Medica, Medicine, Midwifery, Pathology, and Forensic Medicine. New edition. Price 2 s. 6d. cloth; 2s. paper wrapper.

Examinations. Examination Questions on the Medical Sciences, including the Army, Navy and University Examinations. By James Greig Leask, M.B. Abdn. Price 2s. 6 d.

Examinations. Guide to Examinations in Practical Chemistry for the Conjoint Board. By P. A. E. Richards, F.I.C., F.C.S. Price 2s. 6d.

Examinations. Practical Pharmacy for Medical Students; specially adapted for the Examination in Practical Pharmacy of the Conjoint Board. By A. Canpbell Stark, Demonstrator on Materia Medica and Pharmacy at St. George's Hospital. Price 3 s. $6 \mathrm{~d}$., or interleaved for note-taking, 4 s. $6 \mathrm{~d}$.

Exudations. Absorption of Exudations under the Influence of Massage. By A. Kellgren, M.D. Ed., and C. Colonibo, M.D. Turin. Price $1 \mathrm{~s}$. 
Eye. Atlas of Ophthalmoscopy. With an Introduction to the Uses of the Ophthalmoscope. By Prof. O. HAaB, of Zurich. Translated and edited by ERNEST Clarke, M.D. Lond., F.R.C.S., Surgeon to the Central London Ophthalmic Hospital. Text with 64 coloured plates. Price 12s. 6d.

Vol. I.-Hand-Atlas Series.

Eye. Aids to Ophthalmic Medicine and Surgery. By J. Hutchinson, Jun., F.R.C.S., Ophthalmic Surgeon to the Great Northern Hospital. Second edition, cloth. Price 2s. 6d.

Eye. Movable Atlas of the Eye and the Mechanism of Vision. By Prof. G. J. Witkowski. Price 7s. 6d. See Anatomy.

Eye. On Impairment or Loss of Vision from Spinal Concussion or Shock. By JABEZ HogG, MI.R.C.S., Consulting Surgeon to the Royal Westminster Ophthalmic Hospital. Price 1s. 6d.

Eye. Ophthalmic Notes. A Pocket Guide to the Nature and Treatment of Common Affections of the Eye. By A. Vernon Ford, M.R.C.S. Eng., L.K.Q.C.P. I. Price 2s. 6d.

Eye. The Functions of Vision and its Anomalies. By Dr. Giraud Teulon. Translated by Lloyd Owex, F.R.C.S.I., Surgeon to the Midland Eye Hospital, Ophthalmic Surgeon to the Hospital for Sick Children, Birmingham. Price 5s.

Eye. The Relations of the Eye to Diseases of the Body. By MAx KNIES, MI.D., Prof. Extraordinary in the University of Freiburg. Authorised translation by Hr. D. Noyes, M.A., M.D. Illustrated. Price 18s.

"A valuable work."-Bitish Jedical Journal.

"A work of high merit, and of great practical value."- Ner" Fork Hedical Record. Eyes. The following five works have been translated for the National Society
for the Prevention and Cure of Blindness.

The Causes and Prevention of Blindness. By Professor Fuchs, University of Liége. Price 7 s. $6 \mathrm{~d}$.

Mind your Eyes. By F. SArcey. Price 2s, 6d.

How to Preserve the Sight. By Dr. MAGák. Price 6d.

Care of the Eyes. By Heynins and Schröter. Price 6d.

On Spectacles, their History and Uses. By Prof. Horner. Price 6d.

Fasting and Feeding, Psychologically considered. By L. S. Forbes WINSLOW, M.B. Cantab., D.C.L. Oxon. Price 2s.

Fever. On the Endemic Hæmaturia of Hot Climates, caused by the presence of Bilharzia Hæmaturia. By F. H. H. Guillemard, M.A., M.D., F.R.G.S. Price 2s. 
Fever. Text-Book of the Eruptive and Continued Fevers. By JoHN William Moore, B.A., M.D., M. Ch. Univ. Dub., F.R.C.P.I., Professor of Practice of Medicine in the Schools of the Royal College of Surgeons, Physician to the Meath Hospital, Consulting Physician to Cork Street Fever Hospital, Dublin. Price 15s.

Food. Milk and Milk Products. Part I. of the Analysis of Food and Drugs. By T. H. Pearmain and C. G. Moor, M.A. Cantab., Members of the Society of Public Analysts. In five parts. Price 5s. net.

Food. Aids to the Analysis of Food and Drugs. By T. H. Pearmain and C. G. Moor, M.A., F.C.S., Members of the Society of Public Analysts. Price 3s. 6d. cloth; 3s. paper.

Food. The Healthy Manufacture of Bread. By Benjamin Ward Richardson, M.D., F.R.S. Price 6d. paper; cloth, 1s.

Food. The Spirit of Cookery : a Popular Treatise on the History, Science, Practice, and Medical Import of Culinary Art. By J.

L. W. Thudichum, M.D., F.R.C.P. London. Price 6s.

Foot. Movable Atlas of the Foot; its Bones, Muscles, etc. By Prof. Witkowski. Price 7s. 6d. See Anatomy.

Foot. Deformities of the Foot. By W. J. Walsham, M.B., F.R.C.S. Eng., Surgeon to St. Bartholomew's Hospital ; and W. Kent HUGhes, M.B. Lond., M.R.C.S. Price 18s.

"The best illustrated book on the subject."-Glasgow Medical Jounal.

"Will certainly take front as the standard English treatise on deformities of the foot." Australian Medical Journal.

"An excellent book... . well up to date."-British Medical Journal.

Forensic Medicine. Death and Sudden Death. By P. BrouarDEL, Senior Physician of the Faculty of Medicine of Paris. Translated by F. L. Benham, M.R.C.P. Price 10s. 6d.

Forensic Medicine. Aids to Forensic Medicine and Toxicology. By Wm. Murrell, M.D., F.R.C.P. Lond., Physician to, and Lecturer on Materia Medica, Westminster Hospital. Sixth thousand. Price 2s. 6d.

Forensic Medicine. The Student's Handbook of Forensic Medicine and Public Health. By H. Aubrey Husband, M.B., F.R.C.S.E. Sixth edition. Price 10s. 6d. net.

Fractures and Dislocations. Atlas of Traumatic Fractures and Dislocations. By Professor H. Helferich, of Griefswald.

In preparation.

Gall Bladder. Diseases of the Gall-Bladder and Bile Ducts. By A. W. Mayo Robson, F.R.C.S., Hunterian Professor of Surgery and Pathology Royal College of Surgeons, Senior Surgeon to the Central Infirmary, Leeds; Professor of Surgery in the Yorkshire College of the Victoria University. Illustrated with 50 figures. Price 7s. 6 d. 
Geology. Field Geology, with a Section on Palæontology. By W. Hy. Penning, F.G.S., of H.M. Geological Survey, and A. J. Jukes-Browne, B.A., F.G.S. Second edition. Price 7s. 6d.

Geology. Engineering Geology. By the same Author. Illustrated with coloured maps and woodcuts. Price 3s. $6 \mathrm{~d}$.

Gout. Gout and Goutiness; and their Treatment. By Wr. Ewart, M.D. Cantab., F.R.C.P. Lond., M.R.C.S. Eng., Examiner in Medicine at the Conjoint Board. Price 12s. 6d.

Gout. Gout and Rheumatic Gout. By Austin Meldon, M.K.Q.C.P., F.R.C.S.I., Surgeon Jervis Street Hospital, Physician Dublin General Infirmary. Tenth edition. Price 2s. 6d.

Gout. Notes and Conjectures on Gout and certain Allied Diseases. By Dr. Mortiner Granville. Price 1s. net.

Gout. The Nature and Treatment of Gout. By Professor Ebstein, of Göttingen. Translated by J. E. Burton, L.R.C.P.Lond. 3s. 6d. Gout. See also Rheumatism.

Gynæcology. The Diseases of Women and their Treatment. By H. Macnaughton Jones, M.D., F.R.C.S.I., F.R.C.S.E., Examiner in Midwifery, Royal College of Surgeons, Ireland. Seventh edition. Illustrated and enlarged. Price 15s.

Gynæcology. The History and Technique of the Vaginal Radical Operation. By Professor Leopold Landau and Dr. Theowor LANDAU, of Berlin. Authorized Translation by B. L. Easturan, M.D., Assistant in the Landau Frauen-Klinik, Berlin, and Arthur E. Giles, M.D., B.Sc., M.R.C.P. Lond., F.R.C.S. Edin., Assistant Surgeon Chelsea Hospital for Women. Price 7s. 6d.

Gynæcology. Aids to Gynæcology. By Alfred S. GubB, M.D. Paris, M.R.C.S., L.R.C.P., D.P.H., Obstetric Assistant and Gold Medallist Westminster Hospital. Second edition, enlarged. Price, cloth, 2s. 6d. ; paper, 2s.

Gynæcology. Clinical Gynæcology: being a Handbook of Diseases peculiar to Women. By Thos. More Madden, M.D., F.R.C.S. Ed., Obstetric Physician and Gynæcologist, Mater Misericordiæ Hospital, Dublin. Price 12s. 6d.

Gynæcology. On some Symptoms which Simulate Disease of the Pelvic Organs in Women, and their Treatment by Massage. By A. C. F. Rabagliati, M.A., M.D., F.R.C.S. With Photograhic Illustrations. Price 7s. 6d.

Gynæcology. Lawson Tait's Perineal Operations, and an Essay on Curettage of the Uterus. By W. J. Stewart McKay, M.B., M.Ch., B.Sc., Surgeon to the Benevolent Asylum, Maternity Hospital, Sydney, and Lewisham Hospital for Women. Price 3s. 6d. 
Gynæcology. Atlas and Essentials of Gynæcology. By Dr. O. ScHäFFER, of Heidelberg. Illustrated with 173 coloured plates ar. 154 woodcuts. Price $15 \mathrm{~s}$.

Vol. IV.-Hand-Atlas Series.

Hair. A Synopsis of Diseases of the Skin and Hair. By R. GlasgowPatteson, M.B., Surgeon to St. Vincent's Hospital. Price 1s.

Hair. The Hair : its Growth, Care, Diseases, and Treatment. By C. H. LeonarD, A.M., M.D. Illustrated, price $7 \mathrm{~s} .6 \mathrm{~d}$.

Hand. Movable Atlas of the Hand; its Bones, Muscles and Attachments. By Prof. Witkowski. Price 7s. 6d. See Anatomy.

Hay Fever: its Causes, Treatment, and Effective Prevention ; Experimental Researches. By Chas. Harrison Blackley, M.D. Second edition, revised and enlarged. Price 10s. 6d.

Heart. Heart Disease, with special reference to Prognosis and Treatment. By Sir Wm. Broadbent, Bart., M.D. Lond., F.R.S., F.R.C.P. Lond., Physician in Ordinary to H.R.H. the Prince of Wales, Consulting Physician to St. Mary's Hospital and to the London Fever Hospital, and J. F. H. BrodDbent, M.A., M.D. Oxon., M.R.C.P. Price 10s. 6d.

Heart. Adherent Pericardium and its relation to Diseases of the Heart. By Johx H. F, Bronderext, M.D., M.R.C.P., Lond. Price 3s. 6d.

"An excellent clinical summary of twelve cases observed by the author while house physician at St. Mary's."-Biritish Hedical Journal.

Heart. Heart-Studies, Chiefly Clinical. By Wr. Ewart, M.D. Cantab., F.R.C.P., Physician to St. George's Hospital ; Examiner in Medicine at the Royal College of Physicians.

I.-The Pulse-Sensations. A Study in Tactile Sphygmology. Price 15s.

Heart. Clinical Diagrams, with Directions for Recording Cases of Heart Disease. By Geo. Herscheld, M.D. Lond. Price 1s.

Heart. Cycling as a Cause of Heart Disease. By the same Author. Price 1s. 6d.

Histology. Atlas of Human Histology. By Dr. A. Brass, of Göttingen. Translated by R. A. Young, M.D. Lond., B.Sc. Illustrated by 66 Coloured Plates, with 575 figures, 4 to. Half morocco, gilt tops. Price 31s. 6d. net.

Histology. Text-book of Normal Histology : including an Account of the Development of the Tissues and Organs. By Professor Geo. A. Piersol, M.D. Price 15s.

Histology. The Microscopical Examinations of the Human Brain; Methods of Research, ete. By Edwix Goodall, M.D. Lond., Pathologist to the West Riding Asylum. Price 5s. 
Hydatid Disease. The prevalence in Australia of Hydatid Disease. By J. Davis Thomas, M.D. Lond., F.R.C.S. Eng. Edited by A. B. Landon, M.D. Lond. Price 10s.

A Collection of Papers on Hydatid Disease. Being Part II. of the above. By A. B. LANDON. 5s.

Hydrophobia. History, Symptoms, and Treatment of Hydrophobia. By H. R. Bigelow, M.D, Price 4s.

Hygiene. Air, Food, and Exercise. An Essay on the predisposing causes of disease. By A. Rabagliati, M.A., M.B., F.R.C.S. Ed., Consulting Medical Officer Bradford Children's Hospital, and late Senior Honorary Surgeon Bradford Royal Infirmary. Second Edition. Price 5s. net.

Hygiene. A Manual of Naval Hygiene on the Preservation of Health and the Prevention of Disease on board Ship. By JosePh Wilson, M.D. Second edition. 10s. 6d.

Hygiene. Bread, Bakehouses, and Bacteria. By F. J. WALDo, M.D. Cantab., and David Walsh, M.D., C.M. Edin. Price 2s.

Hygiene. Lessons in Military Hygiene and Surgery, from the Franco-Prussian War. Prepared on behalf of Her Majesty's Government. By Surgeon-General Sir Charles Gordon, M.D., K.C.B., Hon. Physician to the Queen. Illustrated, 10s. 6d.

Hygiene. A Manual of Sanitation; or, First Help in Sickness and when Wounded. Alphabetically arranged. By the same Author. Cloth, 2s. 6d.; sewn, 1s.

Hygiene. Healthy Homes. By Stanley Haynes, M.D., M.R.C.S., F.R.G.S. Price 1s. 6d. cloth; 1s. paper.

Hygiene. Hygiene of Beauty, with Prescriptions for the Skin, Teeth, Hair, Perfumes, etc. By Dr. Monin. Translated by Mrs. B. CardWEll. Price 3s. 6d.

Hygiene. Nature's Hygiene. A Manual of Natural Hygiene. By C. T. Kingzftт, F.I.C., F.C.S. Fourth Edition. Price 10s.

Hygiene. Notes on Nuisances, Drains, and Dwellings. By W. H. Penning, F.G.S. Second edition. Price 6d.

Hygiene. The Elements of School Hygiene for the Use of Teachers and Schools. By W. E. Roth, B.A. Price 3s. 6d.

Hygiene. Theatre Hygiene, a study in construction, safety and healthy arrangement. By W. E. Rотн, B.A. Oxon. Price 1s. 6d.

Hygiene. The Sanitation of Public Institutions. The Howard Prize Essay. By R. D. R. Sweeting, M.R.C.S., Medical Superintendent of the Western Fever Hospital. Price 3s. 6d. 
Hygiene. The Catechism of Hygiene and Sanitary Science. Water. By Patrick Hehir, M.D., F.R.S.E., D.P.H. Camb. Price 4s.

Hygiene. The Imperial Health Manual. Being the Authorized English Edition of the Official Health Manual, issued by the Imperial Health Department of Germany. Edited by ANTONY Roche, M.R.C.P. I., etc. Price 2s. 6d. net.

Hypnotism. Psycho-Therapeutics. Treatment by Hypnotism and Suggestion. By J. Tuckey, M.D. Third edition. Price 6s.

Indigestion. Indigestion: an Introduction to the Study of Diseases of the Stomach. By George Herscheld, M.D. Lond. Second edition. Price 5s. net.

Infection. Creameries and Infectious Diseases. By J. J. Welply, M.D., M.Ch., Q.N.I. Second Edition. Price 1s.

Inflammation. The State of the Blood and the Bloodvessels in Inflammation. By T. WharToN JoNES, F.R.C.S., F.R.S., Emeritus Professor of Ophthalmic Medicine and Surgery in University College, London. Price 2s. 6d.

Insanity. Handbook for Attendants on the Insane. Prepared by Authority of the Medico-Psychological Association. Price 2s. New edition in preparation.

Intestinal. Excretory Irritation, and the Action of Certain Internal Remedies on the Skin. By David WALSH, M.D. Edin., Physician to Western Skin Hospital, London, W. Price 3s. 6d.

Kidneys. Vaso-Renal Change rersus Bright's Disease. By J. Milner Fothergill, M.D. Ed. Price 7s. 6d.

Kidneys. Bright's Disease of the Kidneys. By Professor J. M. CHARCot. Translated by H. B. Millard, M.D., A.M. Revised by the Author, with coloured plates, price 7s. $6 \mathrm{~d}$.

Kidneys. Movable Kidney and Intermitting Hydronephrosis. By G. D. Knight, M.D. Price 3s. 6d.

Massage. The Practice of Massage; its Physiological Effects and Therapeutic Uses. By A. Srmoxs Eccles, M.B., M.R.C.S. Eng. Second edition. Price 7s. 6d. net.

Massage. See Rheumatism and Exudations.

Materia Medica. A Dictionary of Materia Medica and Therapeutics. A Synopsis of the Action and Doses of all Drugs in Common Use. By C. Henri Leonard, A.M., M.D., and Thos. Christy, F.L.S., F.C.S. Price 6s. ; half morocco, 8s. 6d.

The Pronunciation, Common Name, Synonyms, English, French, and German. Action and Uses of the Drug, its Antagonists, Incompatibles, Synergists and Antidotes. Its Officinal and Non-officinal preparations, with their Medium and Maximum Doses. 
Materia Medica. Aids to Materia Medica and Therapeutics. By C. E. Armand Semple, B.A., M.B. Cantab., M.R.C.P. Lond.

Part I.-The Non-metallic and Metallic Elements, Alcoholic and Ethereal Preparations, etc. Cloth, 2s. 6d.; paper, $2 \mathrm{~s}$.

Part II.-The Vegetable and Animal Substances. 2s. 6d. and 2s. Part III.-Classification of Remedies. Cloth, 1s. 6d. ; paper, 1s. Part IV.-New Remedies of the British Pharmacopøia. Cloth, 2s. 6ul.; paper, $2 \mathrm{~s}$.

Part V.-Tablets of Materia Medica. Price, cloth, 1s.6d.; paper, 1s. Materia Medica. Notes on Inorganic Materia Medica, and its Chemistry. By J. S. Sharmax. Second edition. Price 1s.6d.

Materia Medica. A Text-Book for Medical and Pharmaceutical Students preparing for Examination. By W. HANDSEL Griffiths, Ph.D., F.C.S., F.R.C.P. Ed. Third edition. Edited by A. S. GubB, M.D. Paris, L.R.C.P. Lond., M.R.C.S., D.P.H., Gold Medallist, Prizeman in Materia Medica, Westminster Hospita!, Price 7s. 6d.

"A book of great value ... a standiard text-book."-Edin. Med. Journal.

"One of the ablest, if not the best work on the subject in our language."- Ned. Press.

Medical Charities. The Reform of Our Voluntary Medical Charities. By Robert Reid Rentoul, M.D. Price 5s.

Medical Chemistry. The Progress of Medical Chemistry. Comprising its Application to Physiology, Pathology and the Practice of Medicine. By J. L. WT. Thudichum, M.D., F.R.C.P. Lond. Price 5s.

Medical Dictionary. See Dictionaries.

Medical Education. Medical Education and Organization. The Hunterian Oration for 1880 . By Walter Rivington, B.A., M.B., F.R.C.S., Surgeon to the London Hospital. Price 1s.

Medical Etiquette. A Few Rules of Medical Etiquette. By a L.R.C.P. Lond. Price 1s.

Medical Jurisprudence. See Forensic Medicine.

Medical Laws. Medical Law for Medical Men: their Legal Relations popularly explained. By Professor Meynotr Tidy, M.B., F.C.S., Barrister-at-Law, and Percy Clarke, LL.B., Solicitor. Leather, gilt edges, price $4 \mathrm{~s}$.

Medical Laws. The Laws Relating to Medical Men. By James GreENwOod, Barrister-at-Law. Price 5s.

"Admirably suited as a guide to the busy practitioner, who frequently runs great risks of becoming involved in legal penalties, in consequence of an imperfect knowledge of the law." - Glasgow Nedical Journal.

Medical Profession. A Guide to the Medical Profession in all its branches, including the Public Services. By C. R. B. KeEtley, F.R.C.S. Second edition. Price 3s. 6d. 
Medical Profession. Guide to the Medical and Dental Professions. By Percival Turner, with a chapter on Lady Doctors. Price 3s. 6d.

"Parents with sons who wish to become doctors will find here all the information necessary on the subject of training and its cost."-Hearth and Home.

Medicine. Aids to Medicine. By Norman Dalton, M.D. Lond., F.R.C.P.

Part I.-General Pathology. The Specific and General Diseases. Price 2s. paper ; 2s. 6d. cloth.

Part II.-Diseases of the Larynx, Lungs, Pleuræ, Pericardium, Heart and Vessels ; the Lymphatics and Spleen; Blood Affections ; the Thyroid and Suprarenal Capsule. Price 2s. and 2s. 6d.

Part III.-Diseases of the Liver, Pancreas, Alimentary Canal, Peritoneum, and Kidney. Price 2s. paper; 2s. 6d. cloth.

Part IV.-Diseases of the Nervous System; the Ear; the Skin. Price $2 \mathrm{~s}$. and 2s. $6 \mathrm{~d}$.

Or in 2 vols., price 4 s. 6 d. each, cloth.

Medicine. Student's Handbook of the Practice of Medicine. By H. Aubrey Husband, M.B., C.M., B.Sc. Price 7s. 6d.

Medicinal Remedies. Notes on Medicinal Remedies. By J, B, Stephenson. Price 1s. 6d.

Medico-Military Services. Our Services under the Crown. A Historical Sketch of the Army Medical Staff. By Surgeon-Major A. Gore, M.D., Sanitary Officer on the Staff. Price $6 \mathrm{~s}$.

Mental Medicine. A Clinical Manual of Mental Diseases, for Practitioners and Students. By A. Campbell Clark, M.D., F.F.P.S.G., Mackintosh Lecturer on Psychological Medicine St. Mungo's College, Glasgow, Medical Superintendent of Lanark County Asylum, Hartwood. Price 10s. 6d.

Mental Medicine. A Practical Manual of Mental Medicine. By Dr. E. Regis, translated by Professor M. B. Hall. Price 10s. Microscopy. Methods of Microscopical Research. By A. C. Cole. Second edition. Price 6s.

Microscopy. Modern Microscopy. A Handbook for Beginners. The Microscope, and Instructions for its Use. Microscopic Objects: How Prepared and Mounted. By M. I. Cross and Martin J. Cole. Second edition, enlarged. Price 3s.6d.

"May be consulted with advantage, especially in difficult points of manipulation."Merrchester Guardian.

"The directions contained are sufficiently minute for ang beginner."-The Nlydical Timus.

"The amateur nicroscopist will find here new and special processes of exploring the world of small things." -Lloyel's Weekly.

Midwifery. See Obstetrics.

Mineral Waters. The Mineral Waters of Europe. A complete Analytical Guide to all the Bottled Waters, their Medicinal and Therapeutic Values. By Professor TichBorne, LL.D., and M. Prosser Janes, M.R.C.P. Lond. Price 3s. 6d.

"Such a book as this is simply invaluable."-The World. 
Mineral Waters. Vichy and its Therapeutical Resources. By Prosser JaMes, M.D., M.R.C.P. Lond. Price 2s. 6d.

Morals. A Physician's Sermon to Young Men. By William Pratt, M.A., M.D., etc. Tenth thousand. Price 1s. cloth.

Morals. Revelations of Quacks and Quackery. By "Detector." Thirtieth thousand. Price 2s.

Morphia. On the cure of the Morphia Habit. By OsCar Jennings, M.D. Paris, F.R.C.S. Eng. Price 2s. 6d.

Mouth. Bacteria of the Sputa and Cryptogamic Flora of the MIouth. By Filandro Vicentini, M.D. Translated by the Rev. E. J. Stutter and Professor E. Saieghi. Price 7s. 6d.

Nerve Supply. Atlas of Cutaneous Nerve Supply. By JACOB HeiberG, M.D., and W. W. WagstafFe, F.R.C.S. With 10 plates in colours. Price 4s. 6 d.

Nervous Diseases. Functional Nervous Diseases, their Causes and Treatment. By Geo. T. STevens, M.D., Ph.D. With plates. Price $12 \mathrm{~s}$.

Nervous Diseases. Clinical Notes on Nerve Disorders in Surgical Practice. By Geo. Wherry, M.A., F.R.C.S. Price 2s.

Nervous Diseases of Children. See Children.

Nervous System. Functional Disorders of the Nervous System in Women. By F. J. McGillicuddy, A.M., M.D. Illustrated with 47 figures, plain and coloured. Price 12s. $6 \mathrm{~d}$.

Nervous System. Atlas of the Normal and Pathological Nervous Systems. By Dr. C. JАKoB. With Introduction by Professor Ad. V. Strimpell. Translated and edited by JosEPH Collins, MI.D. With 78 plates, plain and coloured. Price 15 s. Vol. II.-Hand-Atlas Series.

Neuralgia. The Surgical Treatment of Neuralgia of the Fifth Nerve; being the Lettsomian Lectures for 1892. By Wr. Rose, M.B., B.S. Lond., F.R.C.S., Juint Professor of Surgery in King's College, London, and Surgeon to King's College Hospital. Illustrated. Price 4s. 6d.

Nose. A Handbook of Diseases of the Nose and Pharynx. By JAS. B. BALL, M.D. (Lond.), M.R.C.P., Physician to the West London Hospital. Third Edition, with 54 illustrations. Price 7 s. 6 d.

Nose. Chronic Nasal Obstruction, and Deformities of the upper Jaw, Teeth and Palate. By Mayo Coldier, M.B., M.S. Lond., F.R.C.S. Eng. [In the press.

Nose. Polypus in the Nose and other Affections of the Nasil Cavity: their Successful Treatment. By J.L. W. Thudrchum, M.D., F.R.C.P. Lond. Seventh edition, enlarged. Price 2s. 6d. 
Nose and Throat. Diseases of the Throat and Nose. By F. H. Bosworth, A.M. Cantab., M.D.; Professor of Diseases of the Throat in Bellevue Hospital Medical College, New York, etc. Third edition, with 200 illustrations plain and coloured. Price 25s.

Nursing. Questions and Answers on Nursing, for St. John Ambulance Associations, Nursing Institutes, and Nurses generally. By John W. Martin, M.D., Author of "Ambulance Work." Ninth thousand. Price 1s. 6d. net.

Nursing. Handbook for Attendants on the Insane. Published by authority of the Medico-Psychological Association. With illustrations and Questions for Examinations. Third edition. Price 2s.

Nursing. Handbook of Obstetrical and Gynæcological Nursing, being the Fifth Edition of "A Manual for Midwives." By the late Dr. Fleetwood Churchill. Greatly enlarged by Thos. More Madden, M.D., F.R.C.S. Eng. Price 4s. net.

Obstetrics. Anatomical Atlas of Obstetric Diagrosis and Treatment. By Dr. O. SchaEFFER, of Heidelberg. Illustrated with 145 coloured plates and woodcuts. Price 12s. 6d.

Tol. III.-Hand-Atlas Series.

Obstetrics. Atlas of the Anatomy and Physiology of the Female Generative Organs and of Pregnancy. Text by ArThur E. Giles, M.D., B.Sc. Lond., M.R.C.P. Lond., F.R.C.S. Edin., Assistant Surgeon Chelsea Hospital for Women. Price 3s. net.

Obstetrics. Some Results of Induction of Premature Labour for Contracted Pelvis. By A. A. Warden, M.A., M.B. Price 1s. net.

Obstetrics. Aids to Obstetrics. By Samuel Nall, M.B. Cantab., M.R.C.P. Lond., First Class Honours Nat. Sci. Cambridge, late Resident Obstetric Assistant, St. Bartholomew's Hospital. Price 2s. 6d. cloth; 2s. paper wrapper.

Obstetrics. Hints for the Use of Midwives preparatory to their Examinations. By R. J. M. Coffin, F.R.C.P. Ed. Second Edition, enlarged. Price 2s.

Obstetrics. The Diagnosis and Treatment of Extra-uterine Pregnancy. By JoHn Strahan, M.D., M.Ch. (The Jenks Triennial Prize Essay awarded by the College of Physicians, 1889.) Price 4s. 6d.

Old Age. The Diseases of Sedentary and Advanced Life. By J. Milner Fothergill, M.D., M.R.C.P. Lond. Price 7s. 6d.

Ophthalmology. Aids to Ophthalmic Medicine and Surgery. By J. Hutchinson, Jun., F.R.C.S. Cloth, 2s. 6d. ; paper, 2s. 
Osteology. Osteology for Students, with Atlas of Plates. By ARThur Trehern Norton, F.R.C.S., Surgeon to, and Lecturer on Surgery at, St. Mary's Hospital. Atlas and Text in one volume, 7 s. $6 \mathrm{~d}$. ; in two volumes, 8 s. $6 \mathrm{~d}$.

"The handiest and most complete handbook on Osteology."-The Lancet.

Osteology. Atlas of the Skeleton and its Articulations, showing the Bones and Ligaments of the Human Body and Limbs. By Professor Witkowski. Price 7 s. 6d. See Anatomy.

Overwork. Overwork and Premature Mental Decay : its Treatment. By C. H. F. Routh, M.D., M.R.C.P. Lond. Fourth edition. Price 2s. 6d.

Pathology. A Handbook of Pathological Anatomy and Histology. With an Introductory Section on Post-IIortem Examinations, and the Methods of Preserving and Examining Diseased Tissues. By Francis Delafield, M.D., LL.D., and T. Mitcheli Prunder, M.D. 5th Edition. Illustrated by 365 wood engravings in black and colours. Price 25s.

Pathology. Lectures on Medical Pathology. By H. G. Sutros, M.B., F.R.C.P. Lond., late Physician to, and Lecturer on Pathology at, the London Hospital. Price 5s.

"Such a work is to be accepted with gratitude for the thoughts it contains, and the facts on which they are based."-The Lancet.

Pathology. Handbook of Medical Pathology for the use of Students. By Drs. Herringham, Garrod, and Gow, of St. Bartholomew's Hosnital. Price 7s. 6d.

Pathology. Handbook of Surgical Pathology. Edited by W. J. Walshanr, M.B., F.R.C.S., and D'Arcy Power, M.B. Oxon, F.R.C.S. Second edition. Price 9s.

"An embodiment of the most modern pathological teaching." - The Laincet.

Pathology. Aids to Pathology. By Gilpert A. Bankatyne, M.D. General : Cloth, 1s. 6d. ; paper, 1s.

Special : Cloth, 2s. 6d.; paper, $2 \mathrm{~s}$.

Pathology. Illustrations of Pathological Anatomy ; issued in parts ; each containing 4 plates in colours, with descriptive text by Professors Kast, of Breslau, and Runipel, of Hamburg.

First Series.-Revised and edited by Professor Aruand RUfrer, M.D. Oxon. 12 Parts. Price 48 s. net. Single parts, 6s. each; single plates, 1 s. $6 \mathrm{~d}$. each.

Second Series.-Translater and edited by A. F. Voelcker, M.D. Lond., F.R.C.P. 18 Parts. Price 72s. net. Single parts, 6s. each; single plates, Is. 6d. each. [In course of publication.

Pathology. Examination Cards. Arranged as questions and answers for self-examination. By A. T. SCHOFIELD, M.D., M.R.C.S. Complete in two sets of cards, price 9d. net per set. Mr. Jonathan Hutchinson, F.R.C.S., writes : "It is an invaluable means of self-tuition." 
Pericardium. Adherent Pericardium and its relation to Diseases of the Heart. By J. H. F. Broanbent, M.D., F.R.C.P. Lond. Price 3s. 6d.

Peritonitis. Localised Peritonitis: its Etiology, Diagnosis, and Treatment. By John Wallace, M.D., Professor of Midwifery in the Victoria University. Illustrated. Price 1s.

Pharmacology. A Manual of Pharmacology and Therapeutics. By Wh. Murrell, M.D., F.R.C.P. Lond., Physician to, and Lecturer on Pharmacology at, the Westminster Hospital. Price 10s. 6d.

"There is a joke for every drug in the Pharmacopoia. Indeed, its dry humour is the only dry thing in the 650 pages of the volume."-Medical Reprints.

"The student will find this work an excellent guide. It is full, yet concise."-The Scalpel.

"Indisputably an excellent and comprehensive manual."-Nedical Press and Circular.

Pharmacopœia. A Vest-Pocket Epitome of the British Pharmacopneia. By Russell Coonie, M.A., F.R.C.S. Cloth, price 1s.

Pharmacopœia. Doses and Strengths of the British Pharmacopœia. Price 6d.

Pharmacopœia. The Pocket Pharmacopœia. A Précis of the British Pharmacopœia, including the Therapeutical Action of the Drugs, their Natural Orders and Active Principles. By C. Armand Senple, M.D., M.R.C.P. Second edition, with the Appendix of 1890 . Price $3 \mathrm{~s} .6 \mathrm{~d}$.

Pharmacy. Latin Grammar of Pharmacy, for the use of Students, with an Essay on Latin Prescriptions. By JosePH Ixce, A.K.C.L., formerly Examiner and Member of Council, Pharmaceutical Society. Sixth edition. Price 5s.

"Extremely useful and deservedly suceessful work."-Pharmaceutical Jownal.

Pharmacy. Practical Pharmacy for Medical Students. By A. CAMPPELl Stark, Demonstrator on Materia Medica and Pharmacy at St. George's Hospital. Price 3s. 6d., or interleaved for note-taking, 4s. $6 \mathrm{~d}$.

Pharmacy. Materia Medica and Pharmacy. A Text-Book for Medical and Pharmaceutical Students preparing for Examination. By IV. Handsel Griftiths, Ph.D., F.C.S., F.R.C.P. Ed. Third Edition. Edited by A. S. Gube, M.D. Paris, L.R.C.P. Lond., M.R.C.S., D.P.H. Price 7s. 6u.

Pharynx. See Throat.

Physics. A Manual of Physics. Designed for University and Medical Students. By W. Peddie, D.Sc., F.R.S.E., Assistant Professor of Physics in the University of Edinburgh. New edition. Price 7s. 6 d.

"Altogether worthy of praise. . . . We have no hesitation in giving it higl commenda. tion, feeling well satisfied that it meets a decided want."-Nature.

"Dr. Peddie's manual is deserving of the highest praise."-Lancet.

"The work must be pronounced highly satisfactory, ereditable to anthor and publishers, and caleulated to be useful to the readers for whom it is intended." - Chemicul News.

"The book deserves an extenderl cireulation."-scicnce and Art. 
Phimcsis. Phimosis and Paraphimosis : its Causes, Symptoms, and Treatment; with a description of the ancient rite of circumcision. By L. H. Ormsby, M.D., F.R.C.S.I., Lecturer on Surgery at the Children's Hospital, Dublin. Price ls.

Physiological Chemistry. Students' Notebook for Laboratory work. By A. J. HALL, M.B. Cantab., M.R.C.P. Lond., Lecturer on Physiology at Sheffield School of Medicine. Price 2s. 6 d. net.

Physiological Chemistry. Aids to Physiological Chemistry. By J. L. W. Thudichum, M.D., F.R.C.P. Lond., Lecturer at St. Thomas's Hospital. Price, cloth, 2s. 6d.; sewn, 2s.

Physiological Diagnosis. Physiological Factor in Diagnosis. By J. Milner Fothergill, M.D., M.R.C.P. Lond. Second edition. Price 7s. 6d.

Physiology. A Manual of Physiology. By G. N. Stewart, M.A., M.D., D.Sc. ; lately Examiner in Physiology, University of Aberdeen, and of the New Museums, Cambridge University; now Professor of Physiology in the Western University, Cleveland. With about 300 woodcuts, and 5 coloured plates. $15 \mathrm{~s}$.

Physiology. Aids to Physiology. By B. Thompson Lowne, F.R.C.S., Arris and Gale Lecturer, and Examiner in Physiology, Royal College of Surgeons of England. Fourth thousand, illustrated. In two parts, $2 \mathrm{~s}$. each, or in one vol., cloth, $4 \mathrm{~s}$. $6 \mathrm{~d}$.

Physiology. The Physiologist in the Household. By J. Milner Forhergitl, M.D., M.R.C.P. Part I.-Adolescence. Price 1s. Plant Analysis. See Chemistry.

Polypus in the Nose and other Affections of the Nasal Cavity; their successful treatment. By J. L. W. Thudichun, M.D., F.R.C.P. Lond. Seventh edition, enlarged. Price 2s. 6d.

Population. On the Evils, Moral and Physical, likely to follow, if practices intended to act as Checks to Population be not strongly discouraged and condemned. By C. H. F. Routh, M.D., F.R.C.P. Second thousand. Price 1s.

Posology. Posological Tables : a Classified Chart, showing at a glance the Dose of every Officinal Substance and Preparation. By Handsel Griffiths, Ph.D., L.R.C.P. Fifth edition, revised by Peter W. Squire, F.L.S., F.C.S. Price 1s. ; or mounted on linen, rollers, and varnished, $3 \mathrm{~s} .6 \mathrm{~d}$.

Post-Mortem Examinations. See Pathology.

Post-Mortem Examinations. Operative Surgery on the Cadaver. By Jasper J. Garmany, A.M., M.D., F.R.C.S. Price 8s. 6d.

Premature Burial. Premature Burial. Fact or Fiction? By David Walsh, M.D. Edin., Physician to Western Skin Hospital, London. Price 1s. 6d. net. 
Prescriptions. The Student's Pocket Prescriber. By H. Aubrey Husband, M.B., F.R.C.S.E. Interleaved. Price 1s. 6d. net.

Psychological Medicine in John Hunter's Time and the Progress it has made. By Fletcher Beach, M.B., F.R.C.P. Price 1s.

Psycho-Therapeutics. See Hypnotism.

Public Health. Aids to Public Health. By J. L. W. Thudichum, M.D., F.R.C.P. Lond. Price 1s. 6d. cloth ; 1s. paper.

Public Health. Guide to Sanitary Science Examinations. By Herpert Jones, D.P.H. Cantab. Price 2s. 6d.

Public Health. See also Hygiene and Sanitary Science.

Public Health. The Insperial Health Manual. Being the Authorized English Edition of the Official Health Manual issued by the Imperial Health Department of Germany. Edited by Axtony Roche, M.R.C.P.I. Price 2s. 6d. net.

Public Health. The Practical Guide to the Public Health Acts and Correlated Acts for Officers of Health and Inspectors of Nuisances. By Thos. Whiteside Hine, B.A., M.B. Second edition, in the Press, enlarged.

Pulse. How to Feel the Pulse and what to Feel in it. Practical Hints for Beginners. By William EwarT, M.D., F.R.C.P. Lond., Physician to St. George's Hospital.

[New edition in preparation.

Pulse. The Sphygmograph: its History and use as an aid to Diagnosis. By R. E. Dudgeon, M.D. Price 2s. 6d.

Rabies. See Hydrophobia.

Rectum. Diseases of the Rectum. By Wm. Allingham, F.R.C.S., Senior Surgeon to St. Mark's Hospital, and F. W. Herbert

Allinghal, F.R.C.S., Surgeon to the Great Northern Hospital. Sixth edition. Price 12 s. 6 d.

"An admirable compendium of special knowledge in regard to diseases of the rectum."Hospital.

Remedies. Notes on Medicinal Remedies. By J. B. Stephenson. Price 1s. 6d.

Respiration. The Therapeutics of the Respiratory Passages. By Prosser Janes, M.D., Lecturer on Materia Medica and Therapeutics at the London Hospital. Price 10s. 6d.

"Dr. Prosser James has produced a scholarly treatisc."-New York Nedical Record.

Respiration. Keep your Month Shut; a Popular 'Treatise on Mouth-breathing. By Fred. A. A. Sinth, M.D., C.M. Glas. Price 2s. 6d.

Rheumatism. Rheumatism: its Treatment by Electric Massage, etc., in connection with the Wieshaden Thermal Waters. By Carl Mordhorst, M.D. Kirl. Price 1s. 
Rheumatism. The Tallerman Treatment, by Superheated Dry Air, in Rheumatism, Gout, etc., cases, notes, and medical reports. Edited by Arthur Shadwell, M.A., M.B. Oxon., M.R.C.P. Illustrated by 63 plates. Price $3 \mathrm{~s}$. 6d. net.

Salt. History of Salt, with Observations on its Medicinal and Dietetic Properties. By Evan Marlett Boudy, F.R.C.S., F.S.S., L.R.C.P. Price 2s. 6d.

Sanitary Science. Aids to Sanitary Science. For the Use of Candidates for Public Health Qualifications. By F. J. Allan, M.D., D.P.H. Camb., Assistant Professor of Hygiene, Coliege of State Medicine. Price 4s. 6d.

Skin. Text-book of Diseases of the Skin. By Professor KAPosi, University of Vienna. Authorized translation by Dr. J. C. Johnson. With 84 illustrations. Price 25s.

Skin. Skin Diseases of Infancy and Early Life. By C. M. CAMrpBELL, M.D., C.M. Edin. Price 5s.

Skin. A Synopsis of Diseases of the Skin and Hair. By R. Glasgow Patteson, M.B., Surgeon to St. Vincent's Hospital. Price 1s.

Skin. Some Diseases of the Skin produced by Derangements of the Nervous System. By T. Stretch Dowse, M.D., F.R.C.P.E. Price 2s.

Stricture. Stricture of the Urethra: its Diagnosis and Treatment. By E. Distin Maddick, F.R.C.S. Edin., R.N. Price 4s.

Stone. The Modern Treatment of Stone in the Bladder by Litholapaxy, with Cases Illustrative of the Difficulties and Complications met with. By P. J. Freyer, M.A., M.D., M.Ch., Surg. Lieut.-Col. Bengal Army. Second edition. Price 5s.

"Dr. Freyer's little book is admirable and deserving of all praise." - The Scalpel.

"The work is one to be most strongly commended."-Edinburgh Medical Journal.

Surgery. A Manual of Surgery. By Wr. Rose, M.B., Lond., F.R.C.S., Professor of Surgery in King's College, London, and Albert Carless, M.B. Lond., F.R.C.S., Teacher of Surgery. King's College.

Surgery. Aids to Surgery. By GEorge Brown, M.R.C.S. 2 parts, price 1s. $6 \mathrm{~d}$. cloth, and 1s. sewn, each; or in 1 vol., $2 \mathrm{~s} .6 \mathrm{~d}$. Surgery. Applied Anatomy: Surgical, Medical, and Operative. By John McLachlan, M.D., F.R.C.S. Eng., B.Sc., etc. With 238 illustrations. Two vols., price 18 s.

Surgery. Brain Surgery. By M. Allen Starr, M.D. With 59 illustrations. Price 10s. 6d.

Surgery. Clinical Lectures on Recent Surgery. By ARThuR Trehern Norton, F.R.C.S. Price 3s. 
Surgery. Minor Surgery and bandaging. Questions and Answers for Self-examination. By A. T. ScHOFIELD, M.D. Price 9d. net.

Surgery. The Rules of Aseptic and Antiseptic Surgery. By Professor G. Gerster, M.D. New York Polyclinics. With 248 engravings and 3 coloured plates. Price 15s.

Surgery. The Student's Surgery. By F. J. Gant, F.R.C.S., Consulting Surgeon to the Royal Free Hospital. 850 pp., illustrated. Price 10s. 6d.

Surgery. The Surgery of the Knee-Joint. By C. B. KeEtLey, F.R.C.S., Senior Surgeon to the West London Hospital, and Surgeon to its Orthopædic Department. Cloth, price 1s. 6d.

Surgery. The Text-book of Operative Surgery. By ARTHUR Trehern Norton, F.R.C.S., Surgeon to, and Lecturer on Surgery at, St. Mary's Hospital. With 88 steel plates, after Bernard and Huette. Second edition, half calf, plain, 25s.; coloured, 50s.

Surgery. Aids to Surgical Anatomy. Ry Eugene S. Yonge, M.B. Price 2s. 6d., cloth; 2s., paper.

Surgery. Handbook of Surgical Pathology. By W. J. Walshai, M.B., F.R.C.S., and D'ARCY Power, M.B., F.R.C.S. Second edition. Price $9 \mathrm{~s}$.

"An enbodiment of the most modern pathological teaching."-The Lancet.

Surgery. Notes on Surgical Treatment and Minor Operations, for House Surgeons and Students. By T. F. HoPGood, L.R.C.P., M.R.C.S. Surgeon to the Sunderland Infirmary. Price 2s. 6d.

Surgical Instruments. Chart of Surgical Instruments in Operations. By L. H. Orissy, M.D., F.R.C.S.I., Lecturer on Clinical and Operative Surgery at, and Surgeon to the Children's Hospital, Dublin. Price 10s. ; post free, 10s. 6d.

Syphilis. Syphilis of the Brain and Spinal Cord, its part in the production of Paralysis, Epilepsy, Insanity, and other Mental and Nervous Derangements. By T. Stretch Dowse, M.D., F.R.C.P. Ed. Second edition, illustrated. Price 5s.

Syphilis. Nature and Treatment of Syphilis, and the other socalled Contagious Diseases. By C. R. Drysdale, M.D., M.R.C.P. Lond., F.R.C.S. Eng. Fifth edition. Price 5s.

Teeth. Cure and Preservation of Our Teeth. By Voorint Ditchal, M.D., D.D.S., L.D.S. Price $1 \mathrm{s.}$

"Altogether, this diminutive work deserves a great success."-Science Siftings.

Teeth Extraction, with Notes on the Anatomy and Physiology of the Teeth, for Students. By W. D. Woopburs, L.D.S. Dental Surgeon to the Western Infirmary, Glasgow. Price 5s. 
Temperature. Charts for Recording the Range of Temperature, Pulse, Respiration, History, Progress, and Treatment of Cases. By E. H. Moore, M.D., M.R.C.P. Price 1d. each, 9d. per dozen; or mounted, as a pad, 50,3s. 6d.; 100, 7s.

Therapeutics. Aids to Rational Therapeutics, for the guidance of Practitioners and Senior Students. By J. Milner Fothergill, M.D. Second edition. Price 2s.6d. cloth; 2s. paper wrapper.

Therapeutics. Modern Therapeutics. By GEo. H. NAPheys, A.M., M.D. Revised and enlarged by Drs. Allen Smith and Aubrey Davis. Ninth edition. Two vols., half morocco. Price 30s. each.

Vol. I.-General Medicine, and Diseases of Children.

Vol. II.-General Surgery, Gynæcology, and Obstetrics.

Throat. Affections of the Throat and Larynx. By ARTHuR Trehern Norton, F.R.C.S., Surgeon to St. Mary's Hospital. Second edition, illustrated. Price 6s.

"Short, simple, and thoroughly practical instruction."-Medical Press.

Throat. Diseases of the Throat and Nose. A Practical Guide to Diagnosis and Treatment. With 220 typical illustrations in chromolithography and numerous wood engravings. By LeNNox Browne, F.R.C.S. Edin., Senior Surgeon to the Central London Throat and Ear Hospital. Fourth edition. Price 21s.

"One of the completest treatises on diseases of the throat in any language."-British Medical Journal.

"The best text-book in the English language."-Edinburgh Medical Journal.

Throat. Diseases of the Throat and Nose. By F. H. Bosworth, A.B. Cantab., M.D. New Edition in one vol. Price 25s.

Throat. Muvable Atlas of the Throat, and the Mechanism of Voice, Speech and Taste. By Prof. Witkowski. See Anatomy.

Throat. Tonsillitis in Adolescents. By C. HAIG-Brown, M.D., C.M., Medical Oficer of Charterhouse. Price 3s.

Transfusion. On Transfusion of Blood and Saline Fluids. By C. Egerton Jfnnings, F.R.C.S. With Preface by Sir Spencer Wells, Hart. Third edition. Price 4s. 6d.

Toxicology. Aids to Forensic Medicine and Toxicology. By Williali Murrell, M.D., F.R.C.P. Lond., Physician to, and Lecturer on Materia Medica, Westminster Hospital. Sixth thousand. Price, cloth, 2s. 6d.; paper, 2s.

Tuberculosis. See Consumption.

Ulcers. Ulcers and their Treatment. By W. S. Crawford, B.A. Cantab., F.R.C.S. Ed. Price 1s.; cloth, 1s, 6 d. 
Urinary Diseases. Diseases of the Bladder, Prostate Gland, and Urethra. By F.J. G.NT, F.R.C.S., Senior Surgeon to the Royal Free Hospital. Fifth edition, enlarged. Price 12s. 6d.

Urine. The Urine in Health and Disease, and Urinary Analysis. By D. Campeell Black, M.D. Price 7s. 6d.

Urine. The Urine; a Guide to its Practical Examination. By J. Tyson, M.D., Professor of Morbid Anatomy in the University, and President of the Pathological Society of Philadelphia. Ninth edition, with numerous illustrations. Price 7s. 6d.

Urine. The Quantitive Estimation of Urine. New System of Rapid Analysis for Medical Men and Pharmacists. By J. BARker SuIth, L.R.C.P. Lond. Price 1s.

Vaccination. Lectures on the Theory and Practice of Vaccination. By Robert Cory, M.A., M.D. Cantab., F.R.C.P. London, Physician in charge of the Vaccination Department of St. Thomas's Hospital, Teacher of Vaccination in the University of Cambridge. With 28 tables, 16 chromolithographs, illustrations, and 9 woodcuts. Price 12s. 6d.

Voice. The Philosophy of Voice. Showing the right and wrong Action of the Breath and Vocal Cords in Speech and Song. By Charles Lunn. Fighth edition. Price 5s.

Voice. Artistic Voice in Speech and Song. Dedicated to Mr. Sims Reeves and Mr. Santley. By the same Author. 1s.

Voice. The Voice Musically and Medically Considered. By C. Aruand Semple, M.B. Cantab., M.R.C.P. Lond., Physician to the Royal Society of Musicians. Part I. Musical, price 1s. ; Part II., Medical, price 2s. ; or in one vol., cloth, 3s. 6 d.

Water. The Water Supply of London; or, Suggestions for an Illimitable Supply of $W$ ater to London. By C. H.F. Routh, M.D. Lond., M.R.C.P., Fellow of University College, Lond. Price 1s.

Whooping-Cough. Pathology and Treatment of WhoopingCough. By Thos. M. Dolan, M.D., F.R.C.S.E. Price 3s. 6d.

Women. Functional Disorders of the Nervous System in Women. By T. J. McGillicudoy, A.M., M.D. Plain and Coloured Illustrations. Price 12s. $6 \mathrm{~d}$.

Zoology. Aids to Zoology and Comparative Anatomy. By MaJor Greenwood, M.D., Honours. Price 2s. 6d., and 2s.

From our Dead Selves to Higher Things. A Course of Human Experience and Proyressive Development. By F. J. GANT, F.R.C.S. Second edition. Price 3s. 6d. 
Webster Famity Lib y nary Hedicine Cummings School on wary Medicine at Tufts University 200 Westboro Road North Grafton, MA $\$ 15.36$ 

